"Betting on the Lord: Lotteries and Religiosity in Haiti"

Emmanuelle Auriol, Diego Delissaint, Maleke Fourati, Josepa Miquel-Florensa and Paul Seabright 


\title{
Betting on the Lord: Lotteries and Religiosity in Haiti
}

\author{
Emmanuelle Auriol* \\ Diego Delissaint ${ }^{\dagger}$ \\ Maleke Fourati ${ }^{\ddagger}$ \\ Josepa Miquel-Florensa ${ }^{\S}$ \\ Paul Seabright
}

November 18, 2019

\begin{abstract}
We conducted an experimental study in Haiti testing for the relationship between religious belief and individual risk taking behavior. 774 subjects played lotteries in a standard neutral protocol and subsequently with reduced endowments but in the presence of religious images of Catholic, Protestant and Voodoo tradition. Subjects chose between paying to play a lottery with an image of their choice, and saving their money to play with no image. Those who chose the former are defined as image buyers and those who chose the latter as non-buyers. Image buyers, who tend to be less educated, more rural, and to exhibit greater religiosity, bet more than non-buyers in all games. In addition, in the presence of religious images all participants took more risk, and buyers took more risk when playing in the presence of their chosen images than when playing with other images. We develop a theoretical model calibrated with our experimental data to explore the channels through which religious images might affect risk-taking. Our results suggest that the presence of images tends to increase individuals' subjective probability of winning the lottery, and that subjects therefore believe in a god who intervenes actively in the world in response to their requests.
\end{abstract}

JEL Classification: C93, D81, Z12

Keywords: Risk preferences, Religion, Field Experiment

\footnotetext{
*Toulouse School of Economics (IAST), University of Toulouse, France; emmanuelle.auriol@tse-fr.eu

†University of Quisqueya, Port-au-Prince

$\ddagger$ University of Geneva, Maleke.Fourati@unige.ch

$\S$ Toulouse School of Economics (IAST), University of Toulouse, France; pepita.miquel@tse-fr.eu

"Toulouse School of Economics (IAST), University of Toulouse, France; paul.seabright@tse-fr.eu
} 


\section{Introduction}

How does religious belief affect risk-taking behavior? The question is of great importance in the modern world, since in contrast to the once-dominant secularization hypothesis, religious activities are not an archaic vestige of pre-scientific times, doomed to disappear as education levels rise. Indeed, in the twenty-first century roughly 9 human beings out of 10 are believers in either a monotheistic or polytheistic system. ${ }^{1}$ Religious beliefs and practices are the subject of conscious, reflective choice with considerable consequences for economic and non-economic outcomes. This paper investigates the link between religious belief and risk-taking behavior, using an experiment conducted in Haiti, a country with a high level of religiosity and whose population is exposed to important risks, most of them uninsured. It thereby contributes to a fast-growing literature on the economic analysis of religious behavior.

An important strand of that literature analyzes the effect of religion on economic outcomes via its impact on trust. ${ }^{2}$ It seems also possible that religion may affect economic outcomes through other psychological mechanisms, such as attitudes to risk. The macro-economic literature, in the wake of Weber (1905), has long recognized the potential importance of culture, and especially religion, for economic growth. However, most empirical studies in this literature face a challenge in surmounting endogeneity problems, and it is generally hard to rule out the possibility that confounding factors explain both the religiosity of a population and the growth of its economy. For instance, McCleary and Barro (2006) find in their instrumental variable model that higher GDP per capita causes a reduction in average religiosity. They also find that the relationship between economic

\footnotetext{
${ }^{1}$ According to the World Religion Database, in 2015 the distribution of religious affiliation in the world was as follows: Christians 33.2\%, Muslims 24.0\%, Hindus 13.9\%, Buddhists 7.2\%, other religions 10.1\%, while agnostics and atheists represented solely $9.7 \%$ and $1.9 \%$ of the world population respectively.

${ }^{2}$ There is evidence of the role of religion in building social and economic trust, either by inducing more trustworthy behavior (Norenzayan, 2014; Esteban et al., 2018) or by enabling adherents to signal to others their trustworthiness (Iannaccone, 1994; Irons, 2001; Bulbulia, 2004) and prosociality Levy and Razin (2012). This raises the question of what distinguishes more from less intrinsically trustworthy individuals, and why this should be correlated with religious adherence. One view is that individuals differ in the degree of utility they derive from what happens to others (Becker, 1974). An alternative view is that the most significant way in which individuals differ in their trustworthiness is in their willingness to respect social norms (Fehr et al., 2002; Bernhard et al., 2006). Finally other writers have appealed to self-image concerns (Brekke et al., 2003; Bénabou and Tirole, 2006), which are not precisely reducible to combinations of altruism and respect for norms.
} 
development and religiosity depends on the particular dimension of development. Education has different effects than urbanization, for example (McCleary and Barro, 2006). Even if it were possible to do so in principle, such large-scale studies would have difficulty pinpointing the mechanisms involved. Experimental methods may therefore be helpful in establishing causality.

In this paper we report a study of attitudes to risk, in the form of a lab-in-the-field experiment in which 774 subjects in Haiti played simple lotteries. The participants had to decide how many tokens from their endowment to invest in a lottery presenting a $60 \%$ chance of doubling the bet and a $40 \%$ chance of losing it. They did so both in a standard protocol (which we call hereafter the "neutral" version) and subsequently with reduced endowments but in the presence of religious images from the Catholic, Protestant or Voodoo traditions; these three are the only religions with a substantial presence in Haiti. Subjects then chose between paying to play a fifth lottery with an image of their choice, and saving their money to play it with no image. Their choices were secret. We define subjects who chose to pay to play with an image in the fifth lottery as "buyers". 3

We explore two questions. First, we ask whether buyers as thus defined show different risk behavior from those participants who did not buy an image. We find that they do: buyers bet more than non-buyers in all games (neutral and with images). Secondly, we aim to explore whether the presence of religious images induces a change in the behavior of subjects, and if so whether the change is greater among buyers than among others. Once again the answer is yes to the first question, though there is no significant difference in the magnitude of the change between the two groups.

Next we attempt to explore the mechanisms underlying such behaviors, based on the standard expected utility maximization (EUM) model with a constant relative risk aver-

\footnotetext{
${ }^{3}$ We were also interested in studying trust and religious belief. As part of the same experiment, the 774 subjects also played trust games, both in the standard protocol and with religious images. Their choices of religious image were secret in the lotteries but observed by anonymous partners in the trust games. The trust game and the lottery were played in an order that was randomized by session, and we control in all regressions either for fixed effects or for the order in which the two experiments were played. The results related to the trust game are presented in our companion paper, Auriol et al. (2019).
} 
sion Bernoulli utility function. First, we show that our subjects' behavior is inconsistent with the assumptions underlying EUM models: it is not simultaneously possible that their subjective probability of winning the lottery is the true objective probability as communicated to participants, and that their risk aversion parameter remains constant throughout the experiment. Secondly, our results suggest that religiosity is associated with lower values of the risk aversion parameter across individuals, though we cannot establish the direction of causality. Finally, the presence of images appears to increase participants' subjective probability of winning the lottery. This is consistent with beliefs that God can intervene in the world to deliver an outcome that participants desire (i.e., an interventionist God).

Our study contributes to the existing literature, which we discuss below, in two main ways. First, our experiments involve a large number of ordinary people whom we recruited by traveling into remote areas of Haiti. In contrast, most other related experiments involve a smaller number of participants and/or students of Western universities. Although it was highly challenging to run our experiments in Haiti due to the state of its infrastructure, we believe it was useful in deepening our understanding of how religiosity might shape risk taking behavior in a context of low social trust and weak or non-existent social protection in which most risks go uninsured. ${ }^{4}$

Secondly, this experiment is, to the best of our knowledge, the first to elicit a measure of subjects' religiosity in an incentive compatible way (i.e., through the price they pay to play with a religious image). In other studies, subjects are asked to self-declare their religion, but there is no mechanism for collecting information on the intensity of their beliefs. Yet some people are more religious than others, and if for some reason, those who are more religious also belong to a particular denomination (for instance Muslim immigrants in advanced economies), then experiments might attribute their results to a

\footnotetext{
${ }^{4}$ Chen (2010) finds that religious participation acts as a form of social insurance in Indonesia following the 1997-98 financial crisis. Wickham (2005) reports that religious organizations provide social services and states that "Islamic mobilization in Egypt occurred on the periphery of the formal political system in settings removed from state control." In the case of Haiti, informal institutions, such as religious communities during earlier history and more recently NGOs, substitute for some of the formal institutions of the state (Delisle, 2003, Hurbon, 2004).
} 
religion, while in reality they might simply reflect different levels of faith correlated with the subjects' religion. In fact we do not find any significant denominational differences in what follows. But we do find a strong effect of the intensity of our subjects' religiosity, as measured by their propensity to pay for religious images, on their risk taking behavior.

The paper is structured as follows. We present in Section 2 a review of the literature. We continue in Section 3 with a description of the Haiti field setting and the experimental procedures. Section 4 presents the experimental results, and Section 5 presents a theoretical exploration of the channels of the religiosity effect. Section 6 concludes.

\section{Religion and risk-preferences: links with the liter- ature}

Economists and psychologists have developed a variety of experimental methodologies to elicit and assess individual attitude towards risk (see Harrison and Rutström, 2008, Dave et al., 2010 and Charness et al., 2013 for surveys). The variance in the type and structure of the lotteries used in experiments is large. In particular, some methods are more cognitively demanding than others, which might be a problem in a developing countries such as Haiti where literacy is generally low. ${ }^{5}$ Dave et al. (2010) analyze how and when a simpler but coarser elicitation method may be preferred to a finer but more complex one. Their results, based on a sample of Canadian residents of different age groups, indicate that the more complex measure has overall superior predictive accuracy, but its downside is that subjects exhibit noisier behavior. The authors show that the simpler task should be preferred for subjects who exhibit low numeracy, as it generates less noisy behavior but similar predictive accuracy. For subjects with higher numerical skills, the greater predictive accuracy of the more complex task outweighs the greater noise.

Based on these results we choose for our experiment the Gneezy and Potters (1997) method, used also in Haigh and List (2005), where subjects endowed with a fixed amount

\footnotetext{
${ }^{5}$ The DHS 2012 nationally representative sample shows that $7 \%$ of the population has higher education (i.e., more than secondary education).
} 
of money make a sequence of simple investment decisions in a risky asset (i.e., they choose how much to bet from their endowment in a lottery). The advantages of this method are first, that it is very easy to understand as it builds on subjects' experience of bingo/lottery games, and secondly, that it is incentive compatible (i.e., subjects have no incentive to lie as their choices are secret and affect only themselves). These two advantages explain our choice in the low literacy, low trust context of Haiti.

Of the many, experimental papers on risk aversion assessment in the laboratory, very few test the impact of religious priming on subjects willingness to take risk. A noticeable exception is the paper by Benjamin et al. (2016), which studies, among other things, the risk attitudes of subjects in terms of a series of binary choices between a sure investment and a chance of increasingly larger prizes in a framework initially proposed by Holt and Laury (2002). 827 Cornell University students were enrolled for the experiments. The authors used a subtle priming method by making the subjects complete a sentence unscrambling task. The subjects were randomly assigned to complete a religion-salient or control/neutral sentence unscrambling task. Religion was not mentioned otherwise. After completing the sentence unscramble, the subjects participated in different games. The authors assess, within each of the self-declared religious affiliations in their sample, whether their religious priming treatment affects subjects' attitude towards risk. They find that priming causes increase in risky behavior for Catholic subjects, but has no effect on risk-taking for Protestants.

The role that religious images play in our experiment is not really equivalent to priming as this is normally understood. Priming occurs when an idea or a concept is brought subtly to the attention of experimental subjects without being explicitly mentioned and without any suggestion of relevance to the experiment. In our case subjects are explicitly told they will play with religious images and in one round are allowed to choose to play with religious images for a price. There is no suggestion that the odds of the lottery will be any different, but the choice of subjects to do so is an explicit choice which they may make for reasons of their own. 
What happens in our experiment is that the subjects first play the lottery in a neutral context without any mention of religion. Then we successively add, in a random order, an image of Catholic, Protestant and Voodoo significance in the cup containing the tokens with which they bet. Participants bet secretly. Consistently with Benjamin et al. (2016), we find that our subjects increase their bets in the risky asset in the presence of religious images, but in our case the results are highly significant for all denominations, and there is no denominational difference in the magnitude of the treatment effect. ${ }^{6}$ This last result may reflect the fact that Haiti has no strong divisions across religious denominations: almost all citizens acknowledge either a Protestant or a Catholic faith (with both groups open to Voodoo practices to different degrees), ${ }^{7}$ and that many Haitians appear to switch easily between denominations. ${ }^{8}$

One major advantage of our protocol is that it allows us to obtain a measure of our subjects' intensity of religious belief (and not just their self-declared religious affiliation). Indeed at the end of the 4 lotteries (one neutral followed by three with images) we offer our subjects the opportunity to play another lottery of their choice among the 4 . Since playing in the presence of a religious image involves a cost (either $20 \%$ or $30 \%$ of their endowment) the fact that some subjects choose to play with an image is not a cheap choice. It is revealing of the subject's attachment to the chosen image, which is strongly correlated with the subjects' self declared religion as well as with other self-reported measures of religious practice. Since almost all participants in our experiments declare themselves to be religious to some degree, we interpret the difference between buyers and non-buyers as a difference in intensity of religiosity rather than a difference between the religious and the non-religious.

\footnotetext{
${ }^{6}$ In the financial investment literature Kumar et al. (2011) argue that risk-taking is reduced by Protestantism, whereas Hilary and Hui (2009) argue that risk taking is reduced by both Protestantism and Catholicism. In accordance with Kumar et al. (2011), Benjamin et al. (2016) do find that religious identity norms cause Protestants to become relatively more risk averse than Catholics, but this is because Catholicism increases risk-taking, rather than Protestantism reducing risk-taking as Kumar et al. (2011) hypothesize.

${ }^{7}$ An anecdote during the fieldwork confirmed this characteristic in Haiti. During an interview with a Catholic priest, the latter said that "In good times, a Haitian is either Catholic or Protestant, and in bad times, any Haitian is a Voodooist."

${ }^{8}$ About $49 \%$ of our sample reports to be of Protestant faith, but $50 \%$ of these were not born protestant, having subsequently switched to the Protestant faith.
} 
Our finding that the presence of religious images lead our subjects to take more risk, and that more intensely religious subjects take more risk than less intensely religious subjects, is consistent with recent studies showing that beliefs in divine intervention in the daily lives of individuals can be an important determinant of real and costly social decisions (see Hadnes and Schumacher, 2012; Gershman, 2016; Nunn and Sanchez de la Sierra, 2017). In particular, our results square well with the findings by Nunn and Sanchez de la Sierra (2017) who document the prevalence of beliefs in protective spells in South Congo, arguing that these beliefs helped village residents coordinate a stronger resistance against enemy fighters. If religious priming and religious beliefs lead individuals to be more confident this should also encourage them to fight harder as they might feel protected by God.

In a recent paper, Bentzen (2018) explores the reverse causality, namely how the exposure to unbearable and unpredictable situations, such as natural disasters, affects individual religiosity. The author finds a positive causal relationship at the world level between religiosity and exposure to earthquake risk, which is exogenous. Interestingly religiosity increases more in districts with lower average incomes, education, and population densities. We check this finding in our micro-data sample and find similar results: individuals' willingness to purchase religious images, which is a measure of their religiosity, is correlated with lower education and rural living (i.e., lower density). The explanation for increased religiosity proposed by Bentzen (2018) is the need to cope psychologically with adverse shocks, which is known as the religious coping hypothesis. Bentzen (2018) provides robust evidence in its support. In the context of Haiti, which was hit in 2011 with an unprecedented natural disaster, this would predict an increase in the country's religiosity. It leaves open the question, which we aim to explore, of how heightened religiosity affects individuals' risk taking.

In the last part of the paper we compute subjects' relative risk aversion parameter assuming that they are expected utility maximizers and that their Bernoulli utility function exhibits constant relative risk-aversion. These are indeed the most commonly used assumptions in the empirical literature, which make our results readily comparable with 
previous work (see for instance Harrison et al., 2010, Liu, 2013, De Brauw and Eozenou, 2014, Verschoor et al., 2016). ${ }^{9}$ Our experimental data are inconsistent with the fact that our subjects' risk aversion and their subjective probability of winning the lottery remain constant throughout the experiment. They rather suggest that our subjects update their subjective probability of winning the lottery in presence of religious images. For an in depth discussion of the empirical relevance of the EUM and CRRA assumptions we refer the interested reader to the thorough analytical survey of the literature on elicitation of risk aversion in the laboratory by Harrison and Rutström (2008).

One important issue with experimental data is their external validity. Can we draw conclusions from what we learn in the laboratory about individuals' willingness to take risky gambles in real world situations? The literature suggests that individuals' attitude towards risk in the lab is informative about their attitude towards risk in real life situations. In advanced economies risk aversion measures derived from incentive-compatible experimental choices such as ours are correlated with measures from hypothetical risky choices, which in turn predict risky behaviors such as smoking, drinking, failing to hold insurance, holding stocks rather than Treasury bills, being self-employed, switching jobs, and moving residences (see Barsky et al., 1997, Guiso and Paiella, 2008, Dohmen et al., 2011, and Sahm et al., 2007).

In developing countries, research on risk aversion has focused on farmers, who are generally believed to be risk averse, and neglect their future income when evaluating each risky decision (Schechter, 2007). An extensive literature analyzes how farmers' risk aversion shapes their technology adoption and other saving decisions, crucial for their economic sustainability (see for example Hurley et al., 2010 for a review). Studies by Verschoor et al. (2016) and Liu (2013) focus on whether the risk preferences elicited from the experiments match real world behavior of individuals, for example with respect to technology adoption, and find a statistically significant link between the two.

\footnotetext{
${ }^{9}$ Some of these studies have used lottery games in the field to test whether participants behave according to Expected Utility Theory (EUT), and whether their risk preferences have a CRRA form (see Harrison et al., 2010 for a review of evidence from Ethiopia, India and Uganda and De Brauw and Eozenou, 2014 for a study of farmers from Mozambique).
} 
In our case, we find that buying an image is correlated with higher risk-taking in the lotteries. It is also highly correlated with self-declared religiosity, suggesting consistent findings between the experiment and the survey.

\section{The experiment}

\subsection{Field setting and experimental procedures}

Haiti, the first Caribbean state to achieve independence, occupies the western third of the island of Hispaniola Island, shared with the Dominican Republic. Mountainous with a tropical climate, it is the poorest country in the Americas due to decades of violence and instability. Haiti's Human Development Index value for 2017 is 0.498, which puts the country in the low human development category, positioning it at 168 out of 189 countries and territories. ${ }^{10}$ In Haiti, $50.2 \%$ of the population are multidimensionally poor while an additional $22.2 \%$ live near multidimensional poverty. Political instability has been a characteristic of Haiti's recent history, with entrenched elites controlling economic and political power (Naidu et al., 2015). A Gini coefficient on income of 0.6 makes it one of the most unequal countries on earth.

The study, which was conducted between November 2012 and February 2013, involved 774 subjects in 6 regions of Haiti, who took part in 33 sessions of between 18 and 25 participants each. Figure 1 presents a map of the visited regions. Subjects were recruited from the general population by word of mouth and sessions took place in village halls and schools, not in religious buildings. When subjects arrived they were randomly allocated numbers to ensure anonymity and all records were made with respect to their numbers. They then made a series of experimental choices. We wanted to run two distinct sets of experiments: one on religiosity and trust and the other on religiosity and risk taking. For logistical reasons we opted for running the two sets on the same day as coming back later

\footnotetext{
${ }^{10}$ This number is below the average of 0.505 for countries in the low human development group and below the average of 0.748 for countries in Latin America and the Caribbean. Source: UNDP Human Development Report, 2012. See http://hdr.undp.org/en/composite/trends.
} 


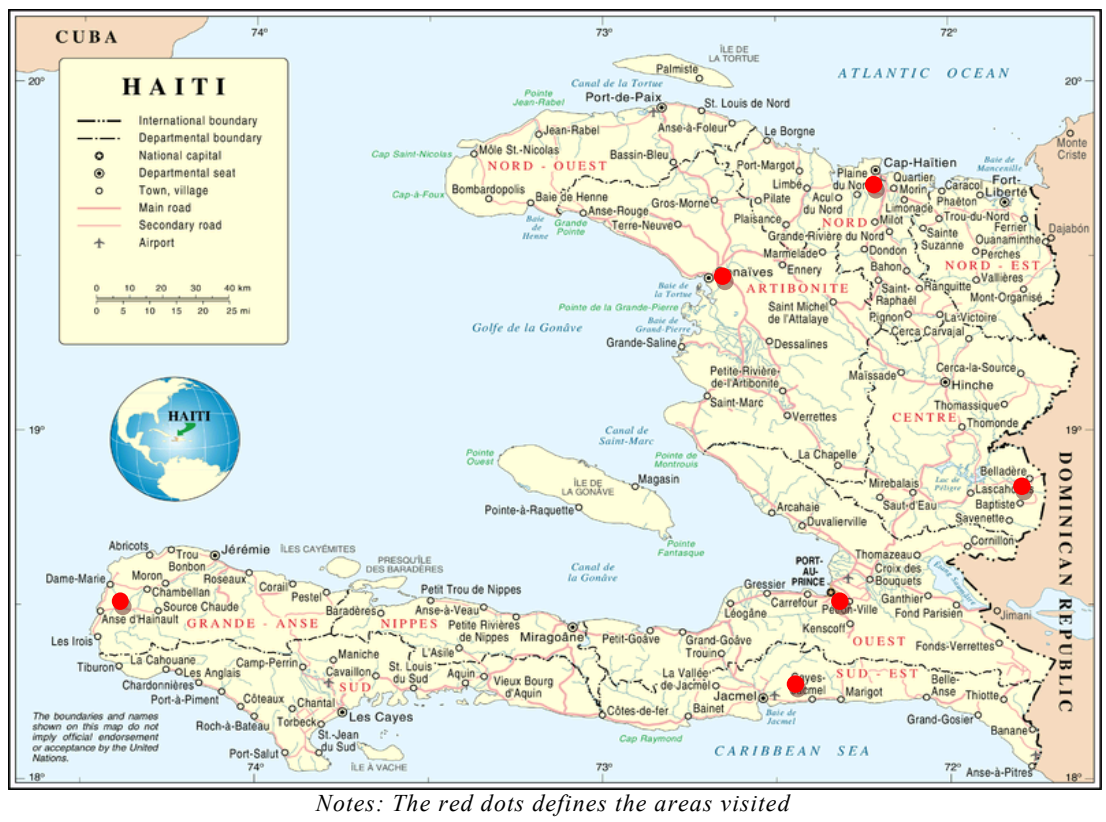

Figure 1: Map of Haiti. The red dots mark the locations where the experiment took place.

to run another set of experiment with a different pool of subjects was too costly in light of the challenging conditions in the country. We therefore randomized at the session level the order of the trust game and the lottery; 372 subjects played the trust game first and 402 played the lottery first. We control in all estmations below either for session fixed effects or for the order of the two experiments.

At the end of the experiment, subjects completed a closed-form questionnaire, with help from project staff for illiterate respondents, and verification of each questionnaire to ensure that subjects had understood the questions. The questionnaire sought to elicit both socio-economic information about each respondent, and also detailed information about religious beliefs and practices, so as to see whether our subjects' willingness to pay to play with images was correlated with other more direct indicators of religiosity. The complete set of questions on religious beliefs and practices is reported in Appendix D.

We compared characteristics of our subject pool with what is to the best of our knowledge the only available nationally representative survey made in Haiti just after the 2010 
earthquake: the 2012 DHS (see Table 1). Our subjects are on average older and better educated than the DHS survey respondents, and we had a smaller proportion of women. But the proportions declaring themselves Catholic and Protestant are similar, with rather more of our subjects declaring themselves Voodooists, which is still a somewhat sensitive matter in Haiti. ${ }^{11}$

\subsection{The lottery choices}

We ran 33 lottery sessions. Each session of the study involved playing a lottery, first in a neutral condition and then in an image treatment that included three religious images: one related to the Catholic religion, one related to the Protestant religion and one related to the Voodoo religion (see Figure 2), in a random order. These images were chosen with the aid of religious leaders of each faith. In the pilot sessions we confirmed that participants unambiguously associated the image with the religion (see figure notes below). Randomization of order of images was at the session level. Appendix A presents the detailed experimental protocol.

Participants played five independent rounds of a lottery game. For each round, the lottery implied a betting decision: subjects were endowed with different amounts of tokens depending on the round (as explained below), and were asked to place any whole number of tokens secretly into a cup. A public draw from an urn containing 6 yellow balls and 4 black balls determined whether the amounts bet would be doubled (yellow) or forfeited (black). It was announced at the start of the session that the public draw for all lotteries would be made at the end, after all the lottery choices had been made. This means that the results of the earlier lotteries cannot have had any impact on the choices made by subjects to pay or not to pay to play with an image.

Figure 3 presents the structure of the five rounds of the lottery game in each session. In the image treatment of the lottery, subjects played the lottery three times with a lower

\footnotetext{
${ }^{11}$ Voodoo practice was subject to clandestinity as it was prohibited and punished during various episodes of the Haitian history. It was recognized as an official religion in 2003, but Voodooists still suffer from social stigma (Métraux, 2016; Hurbon, 2004).
} 


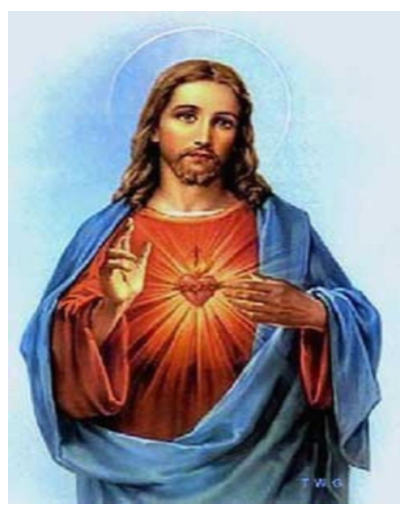

(a) Catholic

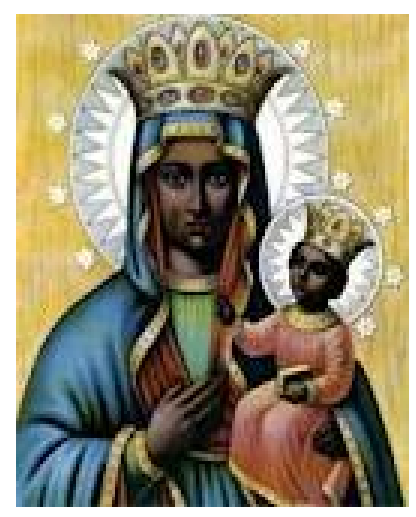

(b) Voodoo

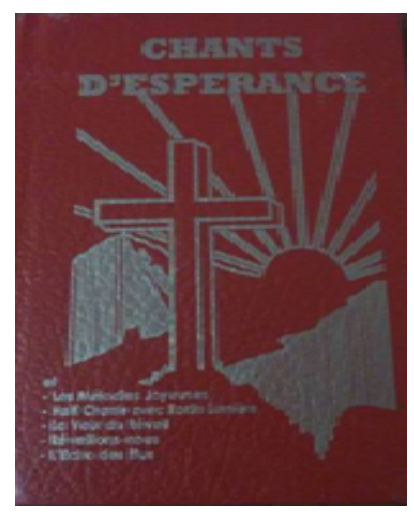

(c) Protestant

The images were attached to plastic cups and presented in the experiment as follows: "We will play with each one of the three colored cups I have here. Before coming here, we went to visit a Catholic priest, a Protestant pastor and a Voodoo priest. Each provided us with an image. As you can see there is a pink one with an image that you will recognize from the Voodoo tradition, an image of the Sacred Heart of Jesus from the Catholic tradition, a picture of the song book "chants d'espérance " that most Protestant churches use."

Figure 2: Religious images of the three religions presented to the subjects

endowment and they all also received, in random order, one of three religious images. The difference in endowments between the two alternatives was therefore the price they paid to be able to bet in the presence of a religious image. We proposed one of two prices, which represented respectively $20 \%$ and $30 \%$ of the original endowment. These prices were randomized at the session level.

\begin{tabular}{ll}
\hline \multicolumn{1}{c}{ Lottery } & Number of tokens \\
\hline 1) Neutral lottery & 10 tokens \\
2) Image lottery 1 & 7 or 8 tokens \\
3) Image lottery 2 & 7 or 8 tokens \\
4) Image lottery 3 & 7 or 8 tokens \\
5) Choice of preferred lottery \& tokens for chosen lottery \\
\multicolumn{2}{c}{ One draw for each lottery 1) to 4) } \\
\hline
\end{tabular}

Figure 3: Structure of the lotteries

Our goal is to learn whether players prefer to play with 10 tokens and a neutral setting, or to play with 8 tokens (or 7 depending on treatment) and with a religious image. 
To elicit their preference across the four lotteries played, subjects played a fifth round. In this fifth round, they were asked to choose one of the four previous lotteries (i.e., neutral or with one of the images). This was done before the lottery draws. Once the players had decided on the lottery to play again, they would receive the corresponding materials and endowment: either the endowment of ten without an image (with a blank note) or the lower endowment with an image of their choice. Players made their choice secretly; other participants could not observe whether subjects had paid for an image nor what image they had paid for if so. ${ }^{12}$ After the materials for this last round were distributed, players would make their bet choice for this last game.

We thus have, for each subject, a record of their behavior in each of the lotteries, with and without religious images. We also know whether they were willing to pay to play with an image, at a price equal to $20 \%$ of endowment or $30 \%$ of endowment, depending on the treatment, which was randomized at the session level. The secrecy of image choices implies that subjects' behavior in the lottery was not driven by the wish to influence other participants, nor by peer pressure.

\section{Experimental Results}

\subsection{Characteristics of image buyers}

A total of $59.6 \%$ of subjects were willing to pay for an image in the lottery. Table 2 reports an econometric estimation of the probability that subjects would buy an image as a function of various subject characteristics, as well as of whether the session took place in a rural or urban area and whether the image price was $20 \%$ or $30 \%$ of their endowment. Compared to non-buyers, image buyers are more likely to live in a rural area and to be illiterate, and less likely to be students. However, they are more likely to have a house made of brick or concrete. These differences indicate that image buyers do not appear to be either at the bottom nor at the top of the wealth distribution; their decision to buy does not seem to represent an income effect. Nor do we see any difference between buyers

\footnotetext{
${ }^{12}$ See protocol in the appendix on the logistics of the procedure.
} 
and non-buyers in terms of religious affiliation. ${ }^{13}$ However, one aspect of religious belief and practice is clearly associated with image-buying, having a statistical effect almost as strong as being illiterate or living in a rural area: whether the subject believes that the last person close to them who died, did so from supernatural causes. The exact wording of the question was "In your opinion, what was the cause of the death of the last close person you lost: (i) Natural or (ii) supernatural?" In other words, image buyers believe more strongly than the other subjects in interventionist gods and spirits.

The most surprising finding in Table 2 is that there is no effect of the image price on willingness to buy. In fact price of the image not only did not affect buying decisions but also had no effect on the share of the endowment bet, conditional on buying. This is shown in Table B4 in Appendix B, which reports the Wilcoxon distribution tests and mean t-tests comparing shares bet with different images prices. Although the share of endowment bet was slightly lower in the high price treatment, the difference was both small in magnitude and statistically insignificant.

\subsection{Comparing bets between Buyers and Non-Buyers}

Figure 4(a) shows the distribution of amounts bet in the neutral lottery (which came first, before subjects played the lotteries with images and therefore before they had to take decisions about whether to pay for an image or not). It shows that subjects who would later reveal themselves to be buyers gambled more than the non-buyers, with a mean of $55 \%$ of endowment bet for buyers compared to $49 \%$ for non-buyers. Figure 4(b) shows the average share of the endowment bet in the lotteries with images. Here the former also bet on average more aggressively than the latter, with a mean of $59 \%$ for buyers compared to $51 \%$ for non-buyers. In both cases the difference is statistically significant at the $1 \%$ level. Table 3 displays the summary statistics of the lotteries by subjects types (all, buyers and non-buyers).

When looking at religious denominations we find no statistically significant difference

\footnotetext{
${ }^{13}$ Table B1 in Appendix B reports a fuller set of comparisons between buyers and non-buyers with respect to various characteristics.
} 


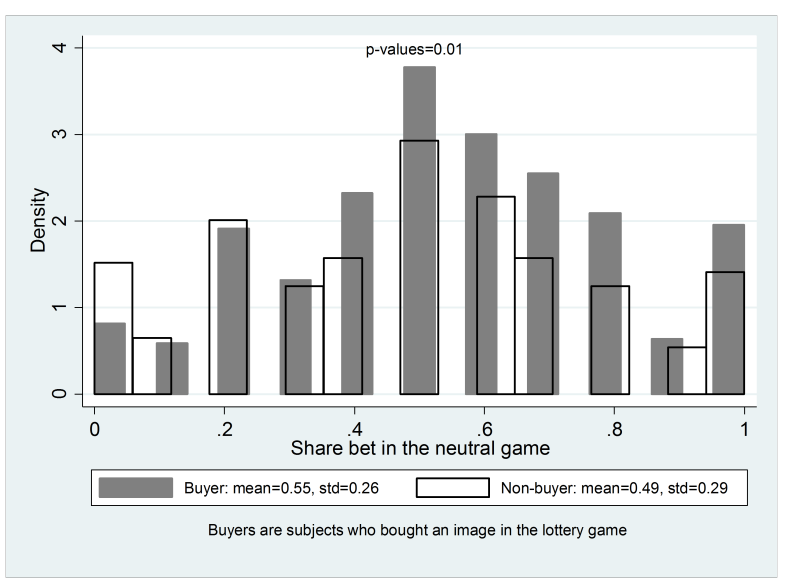

(a) Neutral lotteries

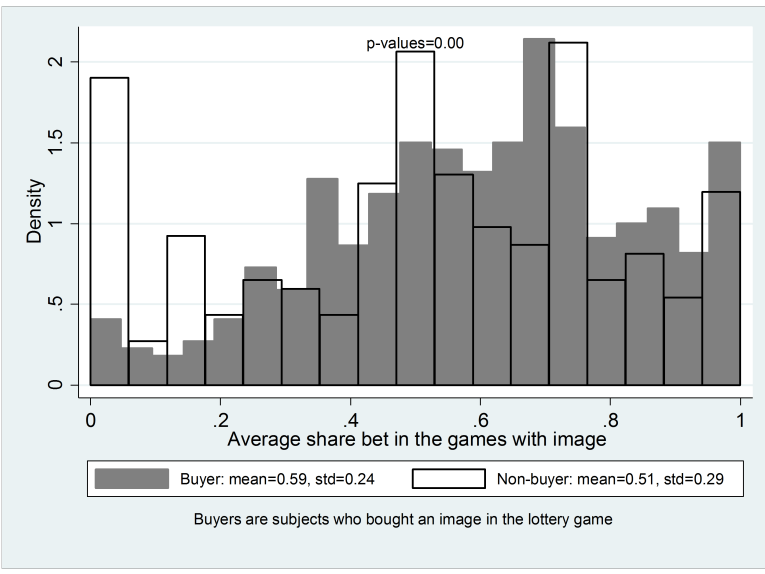

(b) Image lotteries

Notes: The figure presents the Wilcoxon non-parametric test on share of bets across the different samples of subjects. In both figures, we compare subjects that bought the image versus subjects that did not. The left figure compares the share of endowment bet in the neutral lottery, and we find that the test is significant at the $1 \%$ level (Wilcoxon rank test, $\mathrm{p}$-value $=0.0062$ ). The right figure presents the comparison for the shares bet in the lotteries with images. The difference is also significant at the $1 \%$ level (Wilcoxon rank test, $\mathrm{p}$-value $=0.0009$ ). There are more observations in the right figure because there are more games with images than neutral.

Figure 4: Comparison of shares of endowment bet across Buyers and Non-buyers

when comparing the distributions of the bets between them. Table B2 in the Appendix reports the distribution tests comparing bets with different images and for different image prices. ${ }^{14}$ We hence pool the different image lotteries, while controlling for image price in the various econometric specifications.

We analyze econometrically the determinants of differences in betting behaviour between buyers and non-buyers. We include in the regressions both session fixed effects and individual controls. We control for age, higher education, stone house, private car/motorcycle, own a mobile phone, use of internet, whether the subject is protestant, catholic, or voodooist. Since Figures 4(a) and 4(b) reveal some evidence of truncation at 0 and 1 , we run a Tobit specification:

$$
C_{i s}=\beta_{0}+\beta_{1} \text { Image Buyer }_{i s}+\gamma X_{i}+\delta_{s}+\varepsilon_{i s}
$$

where $C_{i s}$ is the choice of individual $i$ playing in session $s$, defined in shares of endowment

\footnotetext{
${ }^{14}$ The only instance in which we find a statistically significant difference is with Voodoo versus Protestant images when image prices are pooled, but this was not significant when we considered the different treatment groups separately.
} 
bet, and ImageBuyer $_{i s}$ is a dummy that takes value 1 if the player bought an image. $X_{i}$ denote individual characteristics, and $\delta_{s}$ are session fixed effects.

Table 4 presents the results of this estimation. The inclusion of 33 session fixed effects involves a substantial loss of statistical power. Yet the coefficient on image buyers is positive and significant. This result is fairly robust.

Column (1) shows the difference between buyers and non-buyers in the neutral lottery: buyers bet on average $4.7 \%$ of their endowment more than non-buyers, a difference that is significant at the $10 \%$ level. The inclusion of individual characteristics, in addition to the 33 session fixed effects, weakens the result, so that the buyer dummy is no longer significant in column (2).

Column (3) does the same for the lotteries with images. Here again buyers bet significantly more than non-buyers: roughly $6 \%$ of their endowment more (out of either 8 or 7 tokens) compared to the non-buyers, a difference that is now significant at the $5 \%$ level. Column (4) shows that this result is robust to the inclusion of individual characteristics.

\subsection{Comparing subjects' behavior with and without images}

The next question we address is how subjects' behavior changes when religious images are included. We compute the difference between the average share of the endowment bet in the lotteries with images and the share of the endowment bet in the neutral case. We report the share of the endowment bet rather than the absolute amount since this is the best method of comparison of betting behavior under different endowments. For instance, decision makers who are expected utility maximizers with constant relative risk aversion would bet the same proportion of their endowment whatever the size of the endowment (for more on this see section 5). As shown in Table 3, on average our subjects increase their share of endowment bet by 4 percentage points (st. dev $=0.21$ ) in the presence of religious images and this difference is highly significant (i.e., at a tiny $1 \%$ level as shown in Table B3) . 
The effect appears to be stronger for buyers, who increase their share bet by 4.5 percentage points (st. $\mathrm{dev}=0.22$ ), than for non-buyers who increase their bet by 2.5 percentage points on average (st. dev $=0.21$ ). However, as can be seen from the Wilcoxon test this difference is not statistically significant, which is confirmed by our regressions (in which we control for session fixed effects) as reported in the two columns of Table 5.

\subsection{Image choices}

In this section we investigate further the image choices that individuals make. First of all, we compare the bets made by individuals across the different image lotteries. Next we consider to what extent their choice of image can be interpreted to reveal information about their own religiosity.

\subsubsection{Image choice and betting}

Figure 5a shows that the distribution of bets in the different image lotteries for non-buyers are almost identical. Figure $5 \mathrm{~b}$ shows that this is not quite so true for image buyers, and in particular that the protestant buyers bet slightly more and the voodoo buyers slightly less than the catholic buyers; these differences are, however, insignificant at the exception of the comparison of voodoo image pairwise with catholic and protestant. By contrast when we compare the bets made by buyers in the presence of their own image and the other images as is shown in Figure 5c, we see that image buyers do bet more in the lottery with the image of their preference, whatever it is. The average bet by an image buyer for his/her chosen image is 0.62 (std. 0.27) while the average bet for the other two remaining images is 0.57 (std. 0.26). These are very significantly different (Wilcoxon test $\mathrm{p}=0.0001)$. 
Figure 5: Distribution of bets in image lotteries

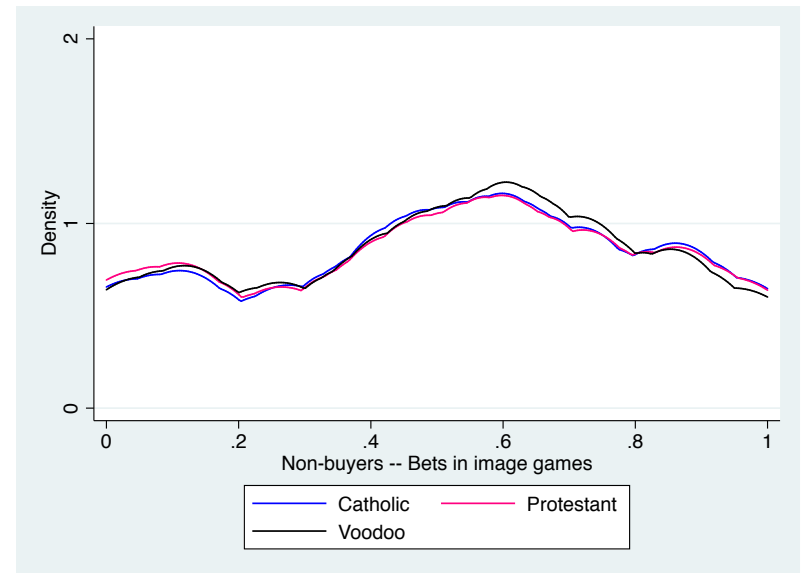

(a) Non-buyers

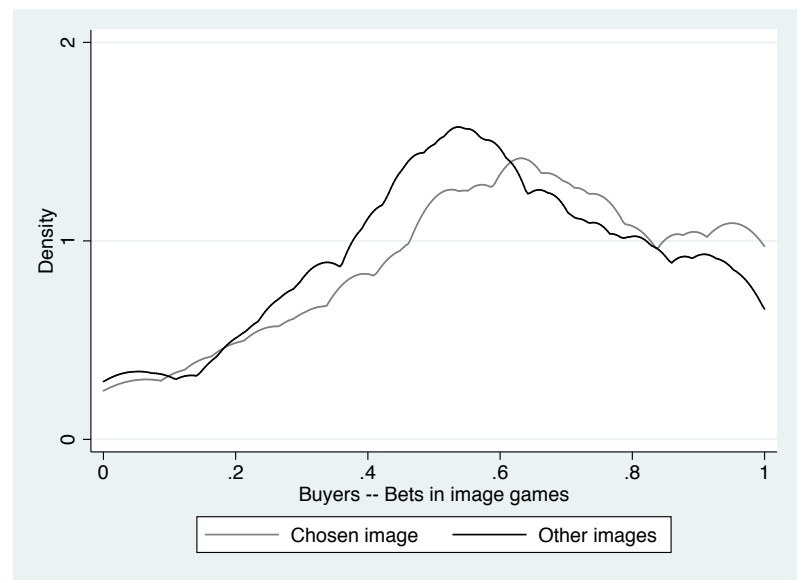

(c) Buyers

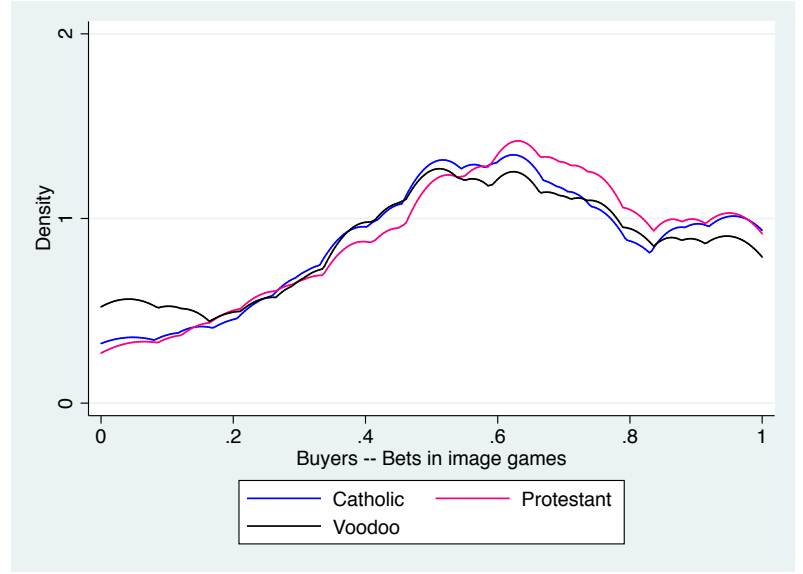

(b) Buyers

Notes: The figures show the kernel density of share of endowment bet for the different image lotteries for buyers and non-buyers.

\subsubsection{Image choice and declared religious affiliation}

The second issue is whether the image choice observed in the lab informs us about actual religious affiliation. Table 6 shows that the willingness to purchase images of a given denomination correlates with subjects' declaring themselves being members of that denomination. Of those who purchased either Protestant or Catholic images, nearly three-quarters declared themselves members of that denomination compared with only around a third of those who did not purchase either image, and the differences are significant at one per cent. Also highly significant is the difference between those who bought and those who did not buy a Voodoo image, though the overall proportions are lower in both cases because few people were willing to declare themselves Voodoo adherents. 


\subsection{Summing up}

We have established first, that buyers of religious images are less educated and more likely to believe in interventionist gods or spirits than non-buyers; secondly that buyers are more willing to take risk than non-buyers in all settings; thirdly, that all the subjects are more willing to take risk in presence of religious images; and fourthly, that buyers' choice of image is strongly correlated with self-declared religious affiliation. These results are fairly robust. They hint at the importance of the presence of religious imagery in shaping individual attitudes towards risk.

There are at least two possible channels through which the effect of images could affect our subjects: via changes in risk-aversion and via changes in the subjective probability of winning. ${ }^{15}$ It is not possible based on our experimental data alone to disentangle the subjective probability from the risk aversion effect. We therefore turn to theory to explore them.

\section{Theoretical exploration of the effect of playing with religious images}

\subsection{The general framework}

To guide the analysis, we model the choice of the individuals in the lottery by assuming that they are expected utility-maximizers (EUM) characterized by a constant relative risk aversion (CRRA) utility function. We show in Appendix $\mathrm{C}$ that the optimal betting strategy $b_{0}$ in the neutral lottery for an EUM individual with the utility function $u(x)=$ $\frac{x^{1-\rho}}{1-\rho}$ with $\rho>0$ and $\rho \neq 1$ and a probability of winning $p>0$ is: $^{16}$

$$
b_{0}=\frac{10(1-q)}{1+q}
$$

\footnotetext{
${ }^{15}$ It is of course possible that subjects might be willing to pay to play with religious images for purely aesthetic or consumption-based reasons. However, if this were the motive it would be hard to understand why subjects' betting behavior should change in the presence of images.

${ }^{16}$ It is easy to check that if $p=0.6$ then $\lim _{\rho \rightarrow 0} b_{0}=10$ and $\lim _{\rho \rightarrow+\infty} b_{0}=0$, which is consistent with the range of the bets we observe.
} 
where

$$
q=\min \left\{1,\left(\frac{1-p}{p}\right)^{\frac{1}{\rho}}\right\}
$$

Condition (2) is equivalent to:

$$
q\left(b_{0}\right)=\frac{10-b_{0}}{10+b_{0}} .
$$

From an empirical point of view, the observation of $b_{i 0}$, the betting strategy of the player $i=1, \ldots 744$, in the neutral lottery allows us to deduce the baseline value of $q_{i 0}=q\left(b_{i 0}\right)$ for each subject.

The assumptions underlying expected utility theory are 1) that the subjects believe in the objective probability of wining the lottery (here that $p=0.6$ ) and 2) that their risk-aversion parameter $\rho$ is constant. Given these assumptions, the betting behavior of players who do not update their probability of winning the lottery, nor change their risk aversion, in presence of the religious image for which they pay a price of $t$ is:

$$
b_{i}\left(t, q_{i 0}\right)=\frac{(10-t)\left(1-q_{i 0}\right)}{1+q_{i 0}}
$$

If the only impact of playing with an image is an income effect, then individuals should not change the percentage of their endowment they allocate to the gamble, and their actual bets $b_{i t}$ should be equal to their optimal bets $b_{i}\left(t, q_{i 0}\right) .{ }^{17}$ We know from Section 4 that our individuals bet a larger share of their endowment in the presence of religious images so that on average $b_{i t}>b_{i}\left(t, q_{i 0}\right)$. Our subjects' behavior is inconsistent with the assumptions underlying EUM theory with CRRA functions.

There are at least two possible ways to explain the discrepancy between the empirical evidence and the model: either participant's risk aversion decreases or their subjective

\footnotetext{
${ }^{17}$ To make comparisons of betting behavior meaningful in the empirical part we computed the percentage of the net endowment that each player gambled in each lottery. Let $b_{i t}$ be the actual bet chosen by the player when $t \in\{0,2,3\}$ (i.e., 0 in the neutral lottery and either 2 or 3 in the image lottery depending on the randomized cost). The percentage of the net endowment gambled by the player is then $x_{i t}=\frac{100 b_{i t}}{10-t}$ for $t \in\{0,2,3\}$. If individuals were EUM then we should observe $x_{i t}=x_{i o}$.
} 
probability of winning increases when religious images are added to the lottery. We therefore explore these two polar cases in turn and discuss their respective relevance in the light of the existing empirical evidence.

\subsection{First possibility: Playing with religious images decreases risk-aversion}

In the first polar case, we assume that the players believe in the objective probability of winning the lottery. Thus, religious images affect their behavior solely through a decrease in their risk-aversion. We calibrate the relative risk aversion parameter $\rho$ of our subjects under the assumption that $p=0.6$ for all. ${ }^{18}$ Our results are summarized in Table 8 . The Table shows that buyers have significantly lower risk-aversion than non-buyers in all cases (neutral or with images). The "Images" column also shows that all types of participants (i.e., "Buyers" and "Non-buyers") have lower risk aversion when they play in the presence of religious images than without, although due to the sample size in the neutral case the result is not statistically significant for the image buyers.

Table 8 shows that the average value of the relative risk aversion parameters $\rho$ is 0.49 in the neutral case. We consider the evidence from the literature with respect to both the magnitude of the risk aversion parameter and its stability over time. With respect to the magnitude, Harrison and Rutström (2008) review the existing evidences on CRRA parameters and propose their preferred range which is 0.5 to 0.8 (e.g., see Table 8 pp 121 in Harrison and Rutström, 2008). The results for our neutral lottery appear therefore to be consistent with the existing literature, albeit at the low range of what Harrison and Rutström (2008) suggest.

By contrast, in the image lotteries the estimates of relative risk aversion are smaller, especially so for the buyers. For instance the average value of $\rho$ for our whole sample is

\footnotetext{
${ }^{18}$ To be more specific, we exploit the betting behavior of the subjects in the neutral lottery, denoted $b_{i 0}$, to compute $q_{i 0}=\frac{10-b_{i 0}}{10+b_{i 0}}$. Setting $p_{0}=0.6$ in the neutral lottery, we deduce from $(3)$ that $\rho_{i}=\frac{\log (1.5)}{-\log \left(q_{i 0}\right)}$ for all $q_{i 0} \in(0,1)$. Similarly we exploit the betting behavior of the subjects in the image lottery, denoted $b_{i t}$, to replace $q_{i 0}$ by $q_{i t}=\frac{10-t-b_{i t}}{10-t+b_{i t}}$ with $t \in\{2,3\}$. We deduce that $\rho_{i t}=\frac{\log (1.5)}{-\log \left(q_{i t}\right)}$ for all $q_{i t} \in(0,1) 0$.
} 
0.44, and the difference with the neutral case is statistically significant at the $5 \%$ level. This last result is at odds with the existing literature on risk aversion.

With respect to the possibility that risk aversion might change over time, especially between rounds of an experiment, Horowitz (1992) and Harrison et al. (2005) provide evidence showing temporal stability of risk attitudes in lab experiments over a period of up to 4 months. This makes us doubt that changes in risk aversion can be the explanation for our subjects' behavior (they played the various lotteries in less than 1 hour). Instead, our results suggest that individuals update their subjective probability of winning the lottery in the presence of religious images, an assumption we explore in the next section.

\subsection{Second possibility: religious images increase the subjective probability of winning}

Based on the background information we collected through conversations with people in Haiti (including some Voodoo priests and priestess), we believe the most plausible channel is that playing with the images changes subjects' subjective probability of winning the lottery. When people turn to God or magic, they pray/pay for a positive outcome. ${ }^{19}$ They do not pray/pay to become more tolerant of failure and risk. In particular, according to Voodooist beliefs, those who follow faithfully the will of their own loa (voodoo spirit) will be aided by the loa, and those who ignore the will of their own loa will be punished (Simpson, 1978). The idea of interventionist spirits is thus deeply embedded in the belief system of Haitians and our image buyers are more prone to such beliefs than non-buyers (e.g., they tend to believe more than non-buyers that death is supernatural).

In the second polar case, we therefore assume that subjects' relative risk aversion parameter, computed in the neutral baseline case, remains constant throughout the ex-

\footnotetext{
${ }^{19}$ Before the early modern era, the concepts of randomness and chance were intertwined with that of fate and God's will. They were for instance discussed by the Greeks and the Maya with no mathematical foundation. It was only in the 16 th and 17 th centuries that Italian and French mathematicians began to discuss the outcomes of games of chance as ratios, which are not intuitive concepts for mathematically illiterate people.
} 
periment, while their subjective probability varies. ${ }^{20}$ Once we have for each individual a measure of their relative risk aversion parameter we compute their subjective probability of winning the lottery in the image treatment. Indeed, in the lottery with religious images we have $q_{i t}=\frac{10-t-b_{i t}}{10-t+b_{i t}}$ where $b_{i t}$ is subject $i$ 's actual bet for price $t \in\{2,3\}$. We deduce from (3) that the individual subjective probability of winning is:

$$
p_{i t}=\frac{1}{1+q_{i t}^{\rho_{i}}}
$$

A summary of our computations is in Table 9. The average subjective probability of winning the lottery in the image treatment is 0.66 , which is statistically different (at the $1 \%$ level) from the baseline value 0.6. In presence of religious images all types of players, buyers and non-buyers alike, overestimate their probability of winning, but the effect is stronger for Buyers. The latter overestimate their probability of wining by 6 percentage points on average (which is $10 \%$ of the baseline value) while Non-buyers overestimate it by "only" 5 percentage points (a difference significant at $5 \%$ ).

In the wake of the seminal work of Kahneman and Tversky (1979), there has been a considerable body of research studying people's perceptions of probability and risk. This literature has uncovered many systematic errors humans make in judging the probabilities of uncertain events. The brain's tendency to find patterns results in heuristics or rules that have consistent bias (see Kahneman et al., 1982). In particular, empirical studies have shown that decision makers do not usually treat probabilities linearly; they tend to overweight small probabilities and underweight large ones. Our analysis suggests that individuals' subjective probability of winning a lottery, in addition to being possibly non linear, is influenced by subjects' religious belief. Individuals who are devout Christians or voodooists might hold the belief that they will be rewarded by favorable outcome from god/spirits. If this is true in our setting, there is a good chance that it is true in other settings as well, especially in regions of the world such as Sub-Saharan Africa and Latin

\footnotetext{
${ }^{20}$ To be more specific, we exploit the betting behavior of the subjects in the neutral lottery game, denoted $b_{i 0}$, to compute $q_{i 0}=\frac{10-b_{i 0}}{10+b_{i 0}} \in[0,1]$. Setting $p_{0}=0.6$ in the neutral lottery, we deduce from $(3)$ that $\rho_{i}=\frac{\log (1.5)}{-\log \left(q_{i 0}\right)}$ for all $q_{i 0} \in(0,1)$. It is worth noting that this direct approach to computing $\rho_{i}$ gives an average value of $\rho$ which is 0.49 (see the mean value of $\rho_{i}$ in Table 9 ).
} 
America, characterized by a high level of religiosity and beliefs in interventionist God (Auriol et al., 2017).

\section{Discussion}

Our experiments show that buyers of religious images, who on the basis of other evidence appear to be more strongly religious people, take more risk in lotteries than non-buyers, who appear to be less religious. Our experiments also show that in the presence of religious images all subjects are more willing to take risk. From a methodological point of view, EUM/CRRA models assume that individuals believe in the objective probability of winning the lottery and that their risk-aversion parameter is constant throughout the experiment. Yet our results robustly show that at least one of these assumptions does not hold when adding religious images to the experiment design. This raises the question of how both religiosity and the presence of religious images (in other words, both temperament and circumstances) might affect individuals' willingness to take risk. There are indeed at least two possible channels as illuminated by the theory: risk aversion and the subjective probability of winning.

Since the existing literature shows that risk aversion is a rather stable characteristic of individuals' preferences, and that people are unable to judge the probabilities of uncertain events accurately, our empirical results suggest that playing with religious images increases individuals' subjective probability of winning the lottery, consistently with the fact that some of them believe in interventionist gods or spirits. Indeed, the average value of the subjective probabilities of winning implied by the betting behavior of our subjects in the image lotteries is significantly higher than the baseline value (at the $1 \%$ level). This study is just a first step towards understanding the channels through which religion affects risk taking behavior. More experimental work is needed to confirm that one of them is through modifying subjective probabilities, as appears to be the case in our experimental setting. 


\section{Acknowledgments}

The authors are grateful for financial support from the European Research Council and the Institute for Advanced Study in Toulouse. The project has received aid from the Agence Nationale de la Recherche (Programme Investissement d'avenir), grant number ANR-17-EURE-0010), and the Swiss National Science Foundation (FNS CONFLICT/172814). The project received approval from the TSE-IAST Ethical review board (2016-11-01). The TSE Review Board had not been created at the time of the fieldwork, but the board agreed to review our experimental protocol retrospectively. The following generously provided comments on the project and on the early findings: Jean-Pierre Albert, Denis Eckert, Nathalie Luca, and seminar audiences in Aix-en-Provence, the University of Delaware, City University London, Davis, Geneva, Heriot-Watt University, Paris, Santa Fe and Toulouse. Youselee Joseph, Heddou Etienne, Enoch Lubin, Eline Theard, and Alix Cayot Dessources provided valuable logistical assistance in Haiti. All errors remain our own. 


\section{References}

Auriol, E., Delissaint, D., Fourati, M., Miquel-Florensa, P., and Seabright, P. (2019). Trust in the image of god: Religion and respect for norms in haiti. Working Paper.

Auriol, E., Lassebie, J., Panin, A., Raiber, E., Seabright, P., et al. (2017). God insures those who pay? formal insurance and religious offerings in ghana. Technical report, Toulouse School of Economics (TSE).

Barsky, R. B., Juster, F. T., Kimball, M. S., and Shapiro, M. D. (1997). Preference parameters and behavioral heterogeneity: An experimental approach in the health and retirement study. The Quarterly Journal of Economics, 112(2):537-579.

Becker, G. S. (1974). A theory of social interactions. Journal of Political Economy, 82(6):1063-1093.

Bénabou, R. and Tirole, J. (2006). Incentives and prosocial behavior. American Economic Review, 96(5):1652-1678.

Benjamin, D. J., Choi, J. J., and Fisher, G. (2016). Religious identity and economic behavior. Review of Economics and Statistics, 98(4):617-637.

Bentzen, J. S. (2018). Acts of god? religiosity and natural disasters across subnational world districts. The Economic Journal (forthcoming).

Bernhard, H., Fehr, E., and Fischbacher, U. (2006). Group affiliation and altruistic norm enforcement. American Economic Review, 96(2):217-221.

Brekke, K. A., Kverndokk, S., and Nyborg, K. (2003). An economic model of moral motivation. Journal of Public Economics, 87(9-10):1967-1983.

Bulbulia, J. (2004). Religious costs as adaptations that signal altruistic intention. Evolution and Cognition, 10(1):19-38.

Charness, G., Gneezy, U., and Imas, A. (2013). Experimental methods: Eliciting risk preferences. Journal of Economic Behavior \& Organization, 87:43-51. 
Chen, D. L. (2010). Club goods and group identity: Evidence from islamic resurgence during the indonesian financial crisis. Journal of Political Economy, 118(2):300-354.

Dave, C., Eckel, C., Johnson, C., and Rojas, C. (2010). Eliciting risk preferences: When is simple better? Journal of Risk and Uncertainty, 41(3):219-243.

De Brauw, A. and Eozenou, P. (2014). Measuring risk attitudes among mozambican farmers. Journal of Development Economics, 111:61-74.

Delisle, P. (2003). Le catholicisme en Haïti au XIXe siècle: le rêve d'une "Bretagne noire”, 1860-1915. KARTHALA Editions.

Dohmen, T., Falk, A., Huffman, D., Sunde, U., Schupp, J., and Wagner, G. G. (2011). Individual risk attitudes: Measurement, determinants, and behavioral consequences. Journal of the European Economic Association, 9(3):522-550.

Esteban, J., Levy, G., Mayoral, L., et al. (2018). Personal liberties, religiosity, and effort. Technical report, Barcelona Graduate School of Economics.

Fehr, E., Fischbacher, U., and Gächter, S. (2002). Strong reciprocity, human cooperation, and the enforcement of social norms. Human nature, 13(1):1-25.

Gershman, B. (2016). Witchcraft beliefs and the erosion of social capital: Evidence from sub-saharan africa and beyond. Journal of Development Economics, 120:182-208.

Gneezy, U. and Potters, J. (1997). An experiment on risk taking and evaluation periods. The Quarterly Journal of Economics, 112(2):631-645.

Guiso, L. and Paiella, M. (2008). Risk aversion, wealth, and background risk. Journal of the European Economic Association, 6(6):1109-1150.

Hadnes, M. and Schumacher, H. (2012). The gods are watching: An experimental study of religion and traditional belief in burkina faso. Journal for the Scientific Study of Religion, 51(4):689-704.

Haigh, M. S. and List, J. A. (2005). Do professional traders exhibit myopic loss aversion? an experimental analysis. The Journal of Finance, 60(1):523-534. 
Harrison, G. W., Humphrey, S. J., and Verschoor, A. (2010). Choice under uncertainty: evidence from ethiopia, india and uganda. The Economic Journal, 120(543):80-104.

Harrison, G. W., Johnson, E., McInnes, M. M., and Rutström, E. E. (2005). Temporal stability of estimates of risk aversion. Applied Financial Economics Letters, 1(1):31-35.

Harrison, G. W. and Rutström, E. (2008). Risk aversion in the laboratory. In Risk aversion in experiments, pages 41-196. Emerald Group Publishing Limited.

Hilary, G. and Hui, K. W. (2009). Does religion matter in corporate decision making in america? Journal of Financial Economics, 93(3):455-473.

Holt, C. A. and Laury, S. K. (2002). Risk aversion and incentive effects. American Economic Review, 92(5):1644-1655.

Horowitz, J. K. (1992). A test of intertemporal consistency. Journal of Economic Behavior \& Organization, 17(1):171-182.

Hurbon, L. (2004). Religions et lien social: l'Église et l'État moderne en Haïti. Les Éditions du Cerf.

Hurley, T. M. et al. (2010). A review of agricultural production risk in the developing world. St. Paul, MN: University of Minnesota, HarvestChoice.

Iannaccone, L. R. (1994). Why strict churches are strong. American Journal of Sociology, 99(5):1180-1211.

Irons, W. (2001). Religion as a hard-to-fake sign of commitment.

Kahneman, D., Slovic, P., and Tversky, A. (1982). Judgment Under Uncertainty: Heuristics and Biases. New York: Cambridge University Press.

Kahneman, D. and Tversky, A. (1979). Prospect theory: An analysis of decisions under risk. Econometrica, 47(2):263-291.

Kumar, A., Page, J. K., and Spalt, O. G. (2011). Religious beliefs, gambling attitudes, and financial market outcomes. Journal of Financial Economics, 102(3):671-708. 
Levy, G. and Razin, R. (2012). Religious beliefs, religious participation, and cooperation. American Economic Journal: Microeconomics, 4(3):121-51.

Liu, E. M. (2013). Time to change what to sow: Risk preferences and technology adoption decisions of cotton farmers in china. Review of Economics and Statistics, 95(4):13861403.

McCleary, R. M. and Barro, R. J. (2006). Religion and political economy in an international panel. Journal for the Scientific Study of Religion, 45(2):149-175.

Métraux, A. (2016). Voodoo in Haiti. Pickle Partners Publishing.

Naidu, S., Robinson, J. A., and Young, L. E. (2015). Social origins of dictatorships: Elite networks and political transitions in haiti.

Norenzayan, A. (2014). Does religion make people moral? Behaviour, 151(2-3):365-384.

Nunn, N. and Sanchez de la Sierra, R. (2017). Why being wrong can be right: Magical warfare technologies and the persistence of false beliefs. American Economic Review, 107(5):582-87.

Sahm, C. R. et al. (2007). Stability of risk preference. Division of Research \& Statistics and Monetary Affairs, Federal Reserve Board.

Schechter, L. (2007). Risk aversion and expected-utility theory: A calibration exercise. Journal of Risk and Uncertainty, 35(1):67-76.

Simpson, G. E. (1978). Black religions in the new world.

Verschoor, A., D Exelle, B., and Perez-Viana, B. (2016). Lab and life: Does risky choice behaviour observed in experiments reflect that in the real world? Journal of Economic Behavior \& Organization, 128:134-148.

Weber, M. (1905). Die protestantische Ethik und der Geist des Kapitalismus. Archiv fur Sozialwissenschaft und Sozialpolitik.

Wickham, C. R. (2005). Mobilizing Islam: Religion, activism and political change in Egypt. Columbia University Press. 


\section{Tables}

Table 1: Comparing experimental sample with general population

\begin{tabular}{lcccccc}
\hline & \multicolumn{9}{c}{ Experimental sample } & DHS 2012 \\
& Obs & Mean & St. Dev. & Min & Max & Mean \\
\hline Rural & 774 & 0.50 & 0.50 & 0 & 1 & 0.62 \\
Female & 774 & 0.31 & 0.46 & 0 & 1 & 0.52 \\
Age & 774 & 31.66 & 11.65 & 15 & 79 & 24 \\
Illiterate & 774 & 0.05 & 0.22 & 0 & 1 & 0.18 \\
High school & 774 & 0.55 & 0.50 & 0 & 1 & 0.40 \\
Higher education & 774 & 0.23 & 0.42 & 0 & 1 & 0.07 \\
Protestant & 774 & 0.49 & 0.50 & 0 & 1 & 0.49 \\
Voodooist & 774 & 0.06 & 0.24 & 0 & 1 & 0.01 \\
Catholic & 774 & 0.42 & 0.49 & 0 & 1 & 0.04 \\
Access to electricity & 774 & 0.57 & 0.50 & 0 & 1 & 0.379 \\
Use Internet & 774 & 0.43 & 0.50 & 0 & 1 & \\
Own mobile phone & 774 & 0.88 & 0.33 & 0 & 1 & \\
\hline
\end{tabular}

Notes: The table reports the summary statistics of our experimental sample conducted in 2013 with the nationally representative sample of the Demographic Health Survey conducted in 2012. 
Table 2: Probability of buying image as a function of various subject and session characteristics

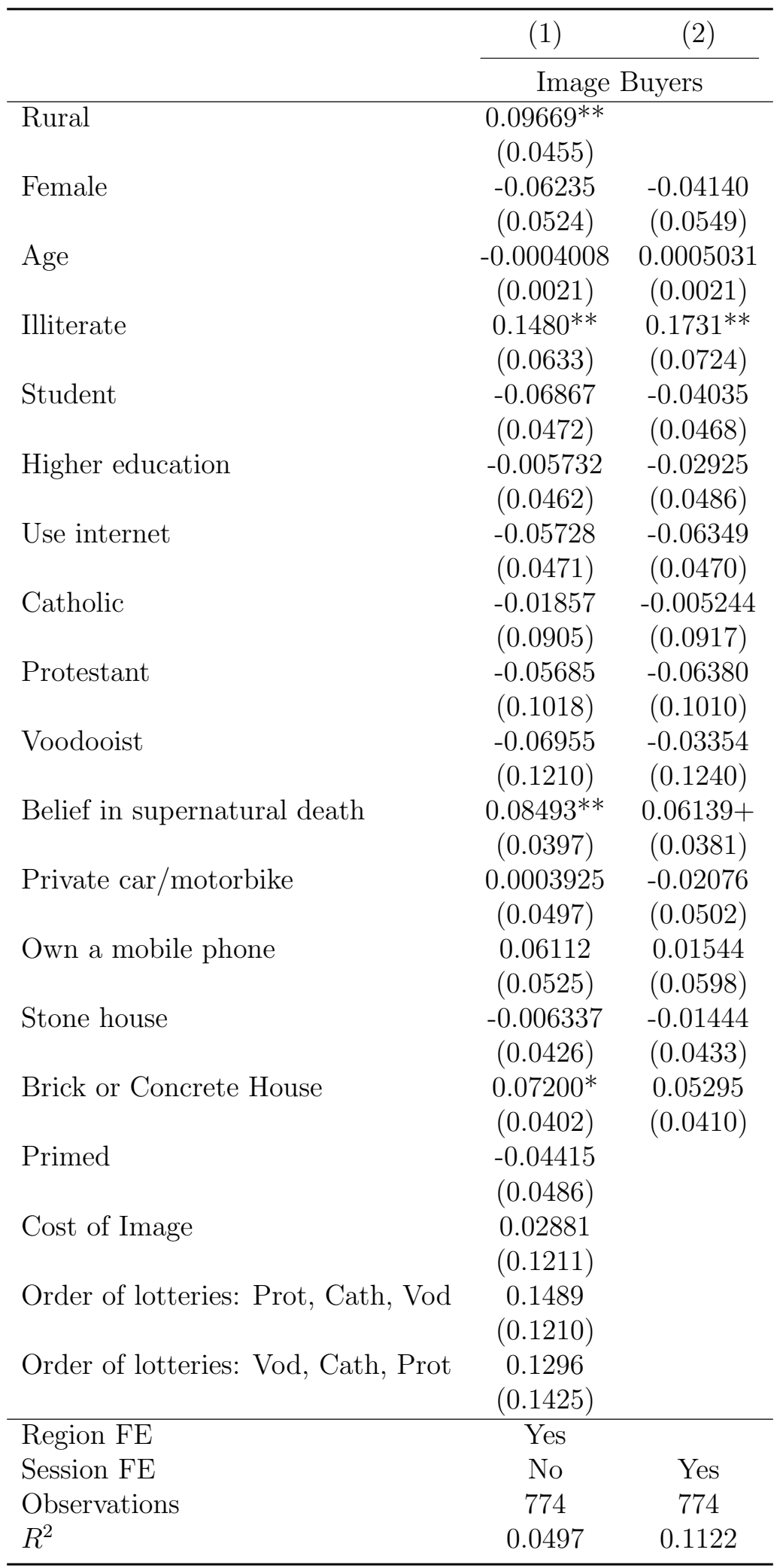

Notes: Probit regression; marginal effects reported. Robust standard errors clustered at session level (33 sessions) in parentheses. Cost of Image equals 1 if price of image is 3 tokens and 0 if it is 2 tokens. In the order of lotteries the omitted group is Cath, Vod, Prot.

** $p<0.01,{ }^{* *} p<0.05,{ }^{*} p<0.10,+p<0.15$. 
Table 3: Average share of the endowment bet

\begin{tabular}{lcccc}
\hline & \multicolumn{3}{c}{ Mean/SE } & Wilcoxon test \\
& All & Image Buyers & Non-Buyers & p-values \\
\hline Neutral & 0.52 & 0.55 & 0.49 & 0.0062 \\
Mean Images & $(0.27)$ & $(0.26)$ & $(0.28)$ & \\
& 0.56 & 0.59 & 0.51 & 0.0009 \\
\hline Difference between Image (mean) & $(0.26)$ & $(0.24)$ & $(0.29)$ & \\
and Neutral games & 0.04 & 0.04 & 0.025 & 0.1673 \\
\hline Voodoo & $(0.21)$ & $(0.22)$ & $(0.21)$ & \\
Protestant & 0.54 & 0.56 & 0.52 & 0.0700 \\
Catholic & $(0.31)$ & $(0.30)$ & $(0.31)$ & \\
& 0.57 & 0.61 & 0.51 & 0.0000 \\
\hline N. & $(0.30)$ & $(0.28)$ & $(0.32)$ & \multirow{2}{*}{0.0007} \\
\hline
\end{tabular}

Notes: The table presents the summary of the bets in each of the lotteries, expressed as share of the endowment, by type of players. The neutral lottery was the one without any image, and Voodoo, Protestant and Catholic are the mean bets for the lotteries with Voodoo, Protestant and Catholic images respectively. Mean Images reports the average share bet in the 3 lotteries with images. The last column reports significance tests (Wilcoxon rank-sum test) of the difference of the distribution for image buyers compared to non-buyers.

Table 4: Share of endowment bet in the lotteries - session fixed effects

\begin{tabular}{lcccc}
\hline & $(1)$ & $(2)$ & $(3)$ & $(4)$ \\
\cline { 2 - 5 } & \multicolumn{2}{c}{ Neutral lottery } & \multicolumn{2}{c}{ Mean image lotteries } \\
\hline Image buyer & $0.04682^{*}$ & 0.04319 & $0.06015^{* *}$ & $0.05881^{* *}$ \\
& $(0.0275)$ & $(0.0277)$ & $(0.0266)$ & $(0.0275)$ \\
Constant & $0.4006^{* * *}$ & $0.5616^{* * *}$ & $0.5228^{* * *}$ & $0.6252^{* * *}$ \\
& $(0.0226)$ & $(0.0619)$ & $(0.0220)$ & $(0.0761)$ \\
\hline Session FE & Yes & Yes & Yes & Yes \\
Individual Controls & No & Yes & No & Yes \\
Observations & 774 & 774 & 774 & 774 \\
Pseudo $R^{2}$ & 0.2856 & 0.3028 & 0.5136 & 0.5296 \\
\hline
\end{tabular}

Notes: Tobit regression. Robust standard errors clustered at session level (33 sessions) in parenthesis ${ }^{* * *} p<0.01,{ }^{* *} p<0.05,{ }^{*} p<0.10$. Controls include: age, higher education, stone house, private car/motorcycle, own a mobile phone, use of internet, protestant, catholic, and voodooist. 
Table 5: Difference in bet in the lotteries - session fixed effects

\begin{tabular}{lcc}
\hline & $(1)$ & $(2)$ \\
\cline { 2 - 3 } & \multicolumn{2}{c}{ Difference between } \\
& Image (mean) and Neutral games \\
\hline Image Buyers & 0.01140 & 0.01288 \\
& $(0.0177)$ & $(0.0177)$ \\
Constant & $0.1283^{* * *}$ & 0.06692 \\
& $(0.0146)$ & $(0.0471)$ \\
\hline Session FE & Yes & Yes \\
Individual Controls & No & Yes \\
Observations & 774 & 774 \\
$R^{2}$ & 0.0899 & 0.0987 \\
\hline
\end{tabular}

Notes: OLS regression. Robust standard errors clustered at session level (33 sessions) in parenthesis *** $p<0.01,{ }^{* *} p<0.05,{ }^{*} p<$ 0.10. Controls include: age, higher education, stone house, private car/motorcycle, own a mobile phone, use of internet, protestant, catholic, and voodooist.

Table 6: Proportions declaring religious affiliation by image bought

\begin{tabular}{lccc}
\hline & \multicolumn{3}{c}{ Image Buyer } \\
& \multicolumn{3}{c}{ Protestant $\begin{array}{c}\text { Catholic } \\
\text { Mean/SE }\end{array}$} \\
\hline Protestant & 0.743 & 0.205 & 0.141 \\
& $(0.44)$ & $(0.405)$ & $(0.350)$ \\
Voodooist & 0.025 & 0.051 & 0.219 \\
& $(0.156)$ & $(0.221)$ & $(0.417)$ \\
Catholic & 0.199 & 0.731 & 0.594 \\
& $(0.400)$ & $(0.445)$ & $(0.495)$ \\
Other religion & 0.033 & 0.019 & 0.062 \\
& $(0.179)$ & $(0.137)$ & $(0.244)$ \\
\hline N. & 241 & 156 & 64 \\
\hline
\end{tabular}

Notes: The table reports the means by images of buyers who declared religious affiliation in the post-experiment questionnaire corresponded to the image in question. 
Table 7: Model calibration: baseline results

\begin{tabular}{lccccc}
\hline & Obs. & Mean & Std. Dev. & Min & Max \\
\hline Variables & & & & & \\
$q_{i 0}$ & 774 & 0.36 & 0.26 & 0 & 1 \\
$q_{i t}$ & 774 & 0.32 & 0.25 & 0 & 1 \\
\hline Risk aversion & & & & & \\
$\rho_{i 0}$ & 659 & 0.49 & 0.39 & 0.14 & 2.02 \\
\hline
\end{tabular}

Notes: $q_{i 0}=\frac{10-b_{i 0}}{10+b_{i 0}}$ where $b_{i 0}$ is subject $i$ 's actual bet in the neutral lottery and $q_{i t}=\frac{10-t-b_{i t}}{10-t+b_{i t}}$ where $b_{i t}$ is subject $i$ 's actual bet for price $t \in\{2,3\}$, and $\rho_{i 0}=\frac{\log (1.5)}{-\log \left(q_{i 0}\right)}$ for all $q_{i 0} \in(0,1)$ is the relative risk aversion parameter based on individuals' bet in the neutral lottery.

Table 8: Implied risk aversion parameter if $p=0.6$

\begin{tabular}{lccccccc}
\hline & \multicolumn{2}{l}{ Neutral lottery } & & Image lottery & & ttest \\
\cline { 2 - 3 } & Obs. & Mean & & Obs. & Mean & & neutral/image \\
\hline All & 659 & 0.49 & & 1770 & 0.44 & 0.015 \\
\hline Buyers & 400 & 0.46 & & 1068 & 0.42 & 0.026 \\
Non-buyers & 259 & 0.52 & 702 & 0.48 & 0.229 \\
\hline ttest buyers/non-buyers (p-value) & & 0.073 & & 0.000 & \\
\hline
\end{tabular}

Notes: Let $q_{i t}=\frac{10-t-b_{i t}}{10-t+b_{i t}}$ where $b_{i t}$ is subject $i$ 's actual bet for price $t \in\{0,2,3\}$. The risk aversion parameter is computed for a CRRA utility function and $p=0.6$. In the neutral case (first column) $\rho_{i 0}=\frac{\log (1.5)}{-\log \left(q_{i 0}\right)}$ for all $q_{i 0} \in(0,1)$. In the image lotteries (second column) $\rho_{i t}=\frac{\log (1.5)}{-\log \left(q_{i t}\right)}$ for all $q_{i t} \in(0,1)$ with $t \in\{2,3\}$ depending on the randomized price of images. A test of equality of the average value of the risk aversion parameter for buyer and non-buyer, Ho: $\rho_{b}=\rho_{n b}$, is presented in the line "ttest buyer/nonbuyer" Similarly a test of equality of the average value of the risk aversion parameter in the neutral and in the image lotteries, Ho: $\rho_{0}=\rho_{t}$, is presented in the column "ttest neutral/image." 
Table 9: Implied subjective probabilities of winning with images

\begin{tabular}{|c|c|c|c|c|c|}
\hline & \multicolumn{2}{|c|}{ Neutral lottery } & \multicolumn{2}{|c|}{ Image lottery } & \multirow{2}{*}{$\begin{array}{c}\text { ttest } \\
\text { neutral/image }\end{array}$} \\
\hline & Obs. & Mean & Obs. & Mean & \\
\hline All & 659 & 0.6 & 1977 & 0.66 & 0.000 \\
\hline Buyers & 400 & 0.6 & 1200 & 0.66 & 0.000 \\
\hline Non-buyers & 259 & 0.6 & 777 & 0.65 & 0.000 \\
\hline ttest buyers/non-buyers (p-value) & & 1 & & 0.02 & \\
\hline \multicolumn{6}{|c|}{$\begin{array}{l}\text { Notes: Let } q_{i t}=\frac{10-t-b_{i t}}{10-t+b_{i t}} \text { where } b_{i t} \text { is subject } i \text { 's actual bet for price } t \in\{0,2,3\} \text {. The risk aversion } \\
\text { parameter is fixed at its baseline value: } \rho_{i 0}=\frac{\log (1.5)}{-\log \left(q_{i 0}\right)} \text { for all } q_{i 0} \in(0,1) \text {. The subjective probability } \\
\text { of winning then is } p_{i t}=1 /\left(1+q_{i t}^{\rho_{i}}\right) \text { with } \rho_{i 0} \text { defined above and } t \in\{0,2,3\} \text {. A test of equality of } \\
\text { the average value of the subjective probability of winning for buyer and non-buyer, Ho: } p_{b}=p_{n b} \text {, is } \\
\text { presented in the line "ttest buyer/nonbuyer" Similarly a test of equality of the average value of the } \\
\text { subjective probability of wining in the neutral and in the image lotteries, Ho: } p_{0}=p_{t} \text {, is presented } \\
\text { in the column "ttest neutral/image." }\end{array}$} \\
\hline
\end{tabular}




\section{Appendices}

\section{A Experimental Protocol}

\section{A.1 Introduction:}

Before the start of the experiment, 25 seats are arranged in the experiment room. Whenever possible, all experimental materials are kept in a nearby room out of the view of the participants. Where that is not feasible, materials are hidden at the end of the room out of the participants' sight.

Once the participants enter the room, they are seated. All the explanations of the experiment director are in creole.

Experiment director (ED afterwards): Thank you for coming. We are a group of university researchers from Toulouse, in France and Quisqueya University. We thank you for coming to this session. Please let us start by giving you very important information for the game.

In a flip chart that will be in view of the participants view during the whole game, the experiment director proceeds to write each of the rules: anonymity, secrecy and serious thought. In the meantime, the assistants distribute the ID numbers.

ED: The first rule we will follow is Anonymity. No personal information will be revealed. You are now given a number in your ID tag; please attach it to your t-shirt. We will never ask you your name; all your decisions will be recorded only with this number. The second important rule is Secrecy. Since all decisions are private, nobody should try to look at anyone else's choices. And the third norm is Serious thought (réfléchi). You need to think seriously about your choices, as real money is involved. You have the possibility of making money, and how much you actually earn depends on your decisions.

The first set of experiment coins is distributed (for the first game) together with the box/cup corresponding to this game to make it easier for the experiment director to ex- 
plain the value of the experimental coins.

ED: You have some plastic coins in your hand, right? You should know that 1 coin=1 point and 1 point=2 gourdes (it is written here on the flip chart). ${ }^{21}$ Then, it is important for you to think about all decisions since that will affect the payments received at the end of the game. Clear for everybody? Any questions?

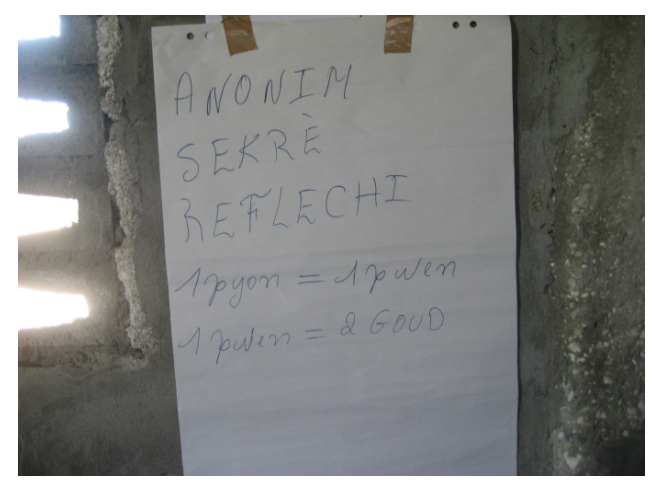

Figure 6: Rules of the game

Then, let us proceed if that is clear for everyone. You are allowed to leave the room at any time you may wish to; this is a voluntary activity. If you leave before the end of the session, we will not be able to calculate your payments.

\section{A.2 Elements included in the experiment: Images and ordering effects}

The experimental session consists of two components: A lottery and a trust game. The images used in both elements are the same for comparability. The structure of each is similar: first a "neutral" version is played, and afterwards it is re-played after the introduction of the images. To check whether the first view of the images affects results, we randomized the order of the two elements.

\footnotetext{
${ }^{21}$ The gourde is the Haitian currency. The payments were calculated so that on average participants would receive around 200 gourdes for a 2- to 3-hour experiment, equivalent to the official minimum wage for an 8-hour day for textile workers.
} 


\section{A.2.1 Lottery}

\section{Neutral version}

The players receive a white paper cup with 10 poker tokens.

ED: Let us start with the first (second) game. You have received a paper cup with 10 tokens inside. Please put the tokens in your hands and count them. How many do you have? Does everyone have 10 tokens? Perfect! Then let me remind you (showing the flip chart) the value of the tokens: 1 token is 1 point, and each point is worth 2 gourdes. Also, let me remind you that all we do here is anonymous: that is why cups have a number that is the same that the number you have handing on your t-shirt.

ED: Now, let me explain you how this game will work. All the tokens you do not put in the cup, are yours to keep. Here you all see a bingo globe that contains 10 balls: 6 yellow and 4 black.

To make sure that it is seen by all participants, a drawing of the cage is made on the flip chart.

ED: Your task is to decide how many of the coins to put into the cup. Why? At the end of the session, we will get a ball out of the bingo globe: if it is yellow, whatever is in the cup will be doubled, but if it is black everything they did put in their cup is lost.

A diagram of what happens for each choice is displayed on the flip chart.

ED: Clear for everyone? Perfect! Now please make your decision as to how many tokens to put in the cup and how many to keep for yourself. The ones you keep for yourself, remember, are already yours, and each has a value of 2 gourdes. For the ones in the cup, we will see what happens with the bingo globe.

ED: Ok, thank you. Now my assistants will pass to collect the cups and the tokens you did not put in the cup.

Assistants pass to collect the cups and the tokens. The collection is made discreetly to as to ensure no participant can guess the actions of the others. 


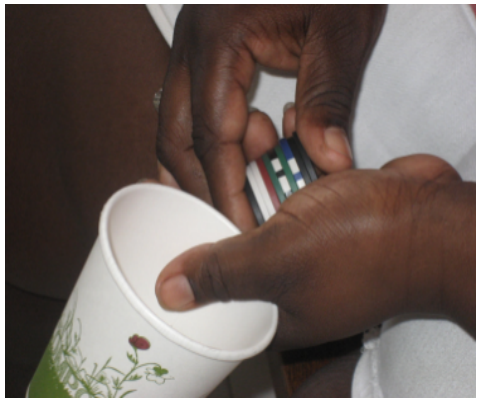

(a) White cup and tokens

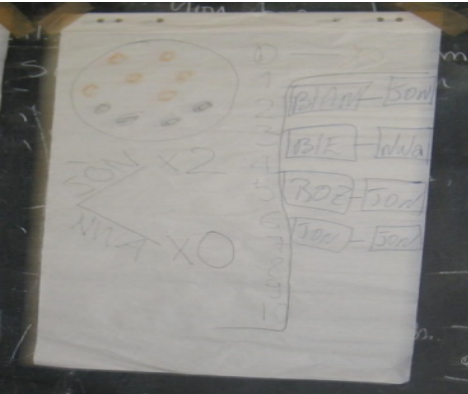

(b) Flip chart

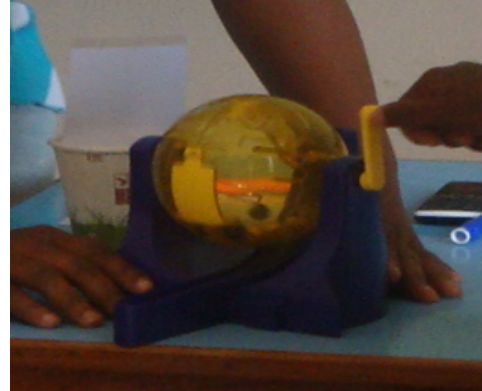

(c) Bingo cage

Figure 7: Presentation of the settings (a), (b) and (c)

Table 10: Order and cost of protection at the risk game

\begin{tabular}{lcccccc}
\hline Session number & S1 & S2 & S3 & S4 & S5 & S6 \\
Cost of protection & $2 / 10$ & $2 / 10$ & $3 / 10$ & $2 / 10$ & $2 / 10$ & $3 / 10$ \\
\hline \multirow{3}{*}{ Order of the games } & Pink & Yellow & Blue & Pink & Yellow & Blue \\
& Yellow & Blue & Pink & Yellow & Blue & Pink \\
& Blue & Pink & Yellow & Blue & Pink & Yellow \\
\hline
\end{tabular}

Note: Blue: Catholic, Pink: Voodoo and Yellow: Protestant

\section{Image versions}

Three colored cups with the images presented in Figure 2 are presented together: a yellow cup for the Protestant image, a blue cup for the Catholic image, a pink cup for the Voodoo image. ${ }^{22}$

ED: Let's continue. What we will do now is, instead of playing with a white cup, we will play with each one of the three colored cups I have here. Before coming here, we went to visit a Catholic priest, a Protestant pastor and a Voodoo priest. Each provided us with an image. As you can see there is a pink one with an image that you will recognize from the Voodoo tradition, an image of the Sacred Heart of Jesus from the Catholic tradition, a picture of the song book "chants d'espérance" that most Protestant churches use. Please count the number of tokens you were given in the cup. You can see that you have 8 (or 7) tokens, so 2 (or 3) less coins than in the first game without an image. However, the logic of the game remains unchanged. Now you can play the same game but with these different cups, and that at the end we will take out one ball from the bingo globe for each

\footnotetext{
${ }^{22}$ Decisions are not affected by the color of the cup but solely by the religious image it corresponds to.
} 
game.

Special care is taken to make sure all participants understand that the lotteries are independent, and that each participant has the same probability of winning. In the image lotteries the order of the cups is randomized to control for ordering effects, and we also changed the cost of protection as a control for different sessions. The procedure of each of the cups is the same as for the white cup: players count the pieces ( 8 or 7 depending on the cost of protection at their session), make their choice, cups and un-bet tokens are collected.

\section{Choice of preferred lottery}

Once the four lotteries are played, the participants are given a white cup with 8 (or 7) tokens depending on the treatment. An experiment assistant presents near the experiment director a box that contains copies of the three images, white cards and experimental tokens.

ED: Now you are allowed to play one more game: you can choose from the 4 games you just played the one you would like to play again. You all have a white cup with tokens, right? Can you please count them? Then, what do you miss if you would like to play the white game? (answer: 2 or 3) And if you want to play the colored games? (answer: 0) In this box that my assistant will bring to each of you, there are the images and there are white cards and tokens. You see the box has a cover so that your neighbors cannot see your choice. Then, if you want to play the pink game again, you take the Voodoo image. If you want to play the blue game again you take the Sacred Heart. If you want to play the yellow game you take the picture of the sons book. If you want to play the white game, you take the white card and two-three tokens. Clear for everybody? Great, then my assistants are coming to each of you with the boxes.

The experiment assistants pass near each participant with the box so each participant can make his/her choice. In Figure 8 the box is designed so that the choice is private and 
cannot be observed by other participants.

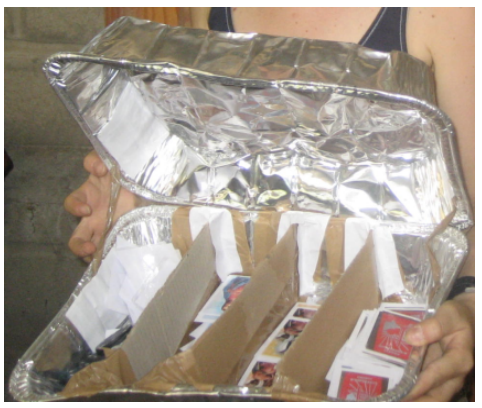

(a) Box for the choice

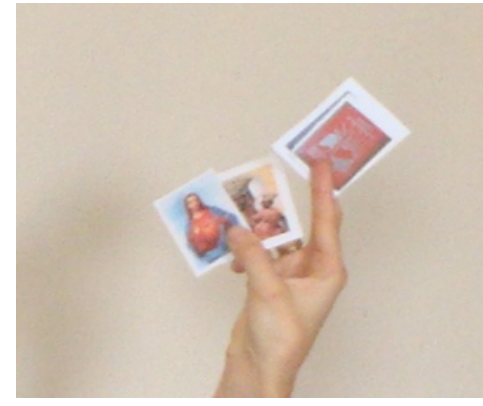

(b) Presentation of the different options

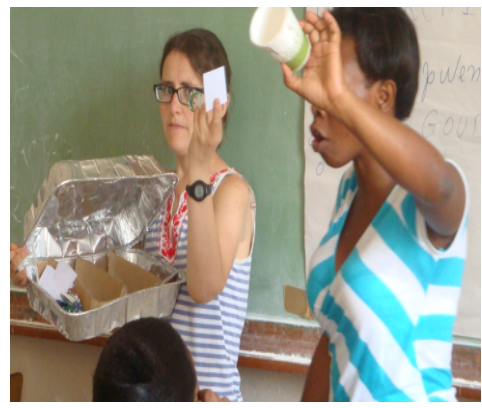

(c) Explanation of the choice

Figure 8: Design of the secret box (a), (b) and (c)

ED: Perfect, now that you all made your choice of which game you want to play again, we will actually play it. So please, as before, decide how many tokens you want to bet leaving them in the cup, and how many you want to keep. My assistants will come to get cups and tokens.

After the participants have made their choice of lottery they are willing to play and have decided how many tokens they want to bid in this lottery, cups with the chosen card and the tokens are collected as are the tokens not played. The bingo globe is turned four times, once for each of the lotteries, and the results are written on the flip charts. 


\section{B Additional tables and figures}

Table B1: Characteristics of Image Buyers and Non-Buyers Compared

\begin{tabular}{|c|c|c|c|c|c|}
\hline \multirow[b]{2}{*}{ Variable } & \multicolumn{2}{|c|}{$\begin{array}{c}(1) \\
\text { Non-Buyers }\end{array}$} & \multicolumn{2}{|c|}{$\begin{array}{c}(2) \\
\text { Buyers }\end{array}$} & \multirow{2}{*}{$\begin{array}{l}\text { Difference } \\
(1)-(2)\end{array}$} \\
\hline & $\mathrm{N}$ & Mean/SE & $\mathrm{N}$ & Mean/SE & \\
\hline Rural & 313 & $\begin{array}{c}0.441 \\
(0.028)\end{array}$ & 461 & $\begin{array}{c}0.540 \\
(0.023)\end{array}$ & $-0.099^{* * *}$ \\
\hline Female & 313 & $\begin{array}{c}0.329 \\
(0.027)\end{array}$ & 461 & $\begin{array}{c}0.297 \\
(0.021)\end{array}$ & 0.032 \\
\hline Age & 313 & $\begin{array}{l}31.109 \\
(0.613)\end{array}$ & 461 & $\begin{array}{l}32.043 \\
(0.567)\end{array}$ & -0.935 \\
\hline Use internet & 313 & $\begin{array}{c}0.470 \\
(0.028)\end{array}$ & 461 & $\begin{array}{c}0.406 \\
(0.023)\end{array}$ & $0.064^{*}$ \\
\hline \multicolumn{6}{|l|}{ Education: } \\
\hline Illiterate & 313 & $\begin{array}{c}0.035 \\
(0.010)\end{array}$ & 461 & $\begin{array}{c}0.063 \\
(0.011)\end{array}$ & $-0.028^{*}$ \\
\hline High school & 313 & $\begin{array}{c}0.572 \\
(0.028)\end{array}$ & 461 & $\begin{array}{c}0.536 \\
(0.023)\end{array}$ & 0.036 \\
\hline Higher education & 313 & $\begin{array}{c}0.256 \\
(0.025)\end{array}$ & 461 & $\begin{array}{c}0.213 \\
(0.019) \\
\end{array}$ & 0.043 \\
\hline \multicolumn{6}{|l|}{ Religion: } \\
\hline Protestant & 313 & $\begin{array}{l}0.518 \\
(0.028)\end{array}$ & 461 & $\begin{array}{c}0.477 \\
(0.023)\end{array}$ & 0.040 \\
\hline Voodooist & 313 & $\begin{array}{c}0.061 \\
(0.014)\end{array}$ & 461 & $\begin{array}{c}0.061 \\
(0.011)\end{array}$ & -0.000 \\
\hline Catholic & 313 & $\begin{array}{c}0.399 \\
(0.028)\end{array}$ & 461 & $\begin{array}{c}0.434 \\
(0.023)\end{array}$ & -0.034 \\
\hline Believe in supernatural death & 313 & $\begin{array}{c}0.243 \\
(0.464)\end{array}$ & 461 & $\begin{array}{c}0.314 \\
(0.429)\end{array}$ & $-0.071^{* * *}$ \\
\hline \multicolumn{6}{|l|}{ Occupation: } \\
\hline Unemployed & 313 & $\begin{array}{c}0.169 \\
(0.021)\end{array}$ & 461 & $\begin{array}{c}0.152 \\
(0.017)\end{array}$ & 0.017 \\
\hline Student & 313 & $\begin{array}{c}0.383 \\
(0.028)\end{array}$ & 461 & $\begin{array}{c}0.315 \\
(0.022)\end{array}$ & $0.069^{* *}$ \\
\hline Civil servant & 313 & $\begin{array}{c}0.128 \\
(0.019)\end{array}$ & 461 & $\begin{array}{c}0.100 \\
(0.014)\end{array}$ & 0.028 \\
\hline Peasant \& Fisherman & 313 & $\begin{array}{c}0.304 \\
(0.026)\end{array}$ & 461 & $\begin{array}{c}0.354 \\
(0.022)\end{array}$ & -0.050 \\
\hline \multicolumn{6}{|l|}{ Asset ownership: } \\
\hline Television & 313 & $\begin{array}{c}0.444 \\
(0.028)\end{array}$ & 461 & $\begin{array}{c}0.432 \\
(0.023)\end{array}$ & 0.012 \\
\hline Private-car/motorbike & 313 & $\begin{array}{c}0.147 \\
(0.020)\end{array}$ & 461 & $\begin{array}{c}0.145 \\
(0.016)\end{array}$ & 0.002 \\
\hline Bicycle & 313 & $\begin{array}{c}0.029 \\
(0.009)\end{array}$ & 461 & $\begin{array}{c}0.067 \\
(0.012)\end{array}$ & $-0.038^{* *}$ \\
\hline Own mobile phone & 313 & $\begin{array}{c}0.882 \\
(0.018)\end{array}$ & 461 & $\begin{array}{c}0.874 \\
(0.015)\end{array}$ & 0.008 \\
\hline \multicolumn{6}{|l|}{ Dwelling characteristics: } \\
\hline Access to electricity & 313 & $\begin{array}{c}0.565 \\
(0.028)\end{array}$ & 461 & $\begin{array}{c}0.573 \\
(0.023)\end{array}$ & -0.007 \\
\hline Stone house & 313 & $\begin{array}{c}0.300 \\
(0.026)\end{array}$ & 461 & $\begin{array}{c}0.254 \\
(0.020)\end{array}$ & 0.047 \\
\hline Brick or concrete house & 313 & $\begin{array}{c}0.419 \\
(0.028)\end{array}$ & 461 & $\begin{array}{c}0.469 \\
(0.023)\end{array}$ & -0.050 \\
\hline Corrugated iron roof & 313 & $\begin{array}{l}0.770 \\
(0.024)\end{array}$ & 461 & $\begin{array}{c}0.744 \\
(0.020)\end{array}$ & 0.026 \\
\hline No land ownership & 309 & $\begin{array}{c}0.576 \\
(0.028) \\
\end{array}$ & 457 & $\begin{array}{c}0.551 \\
(0.023) \\
\end{array}$ & 0.025 \\
\hline \multicolumn{6}{|l|}{ Community involvement: } \\
\hline Church organization & 313 & $\begin{array}{c}0.511 \\
(0.028)\end{array}$ & 461 & $\begin{array}{c}0.525 \\
(0.023)\end{array}$ & -0.014 \\
\hline Social \& political association & 313 & $\begin{array}{c}0.482 \\
(0.028)\end{array}$ & 461 & $\begin{array}{c}0.456 \\
(0.023)\end{array}$ & 0.027 \\
\hline Cooperative (fonkozé) & 313 & $\begin{array}{l}0.086 \\
(0.016)\end{array}$ & 461 & $\begin{array}{c}0.076 \\
(0.012)\end{array}$ & 0.010 \\
\hline Rosca (sol) & 313 & $\begin{array}{c}0.144 \\
(0.420)\end{array}$ & 461 & $\begin{array}{c}0.121 \\
(0.015)\end{array}$ & 0.022 \\
\hline
\end{tabular}

Notes: These summary statistics are based on the participants' responses to the survey. The value displayed for t-tests are the differences in the means across the groups. *** $p<0.01, * * p<0.05, * p<0.10$. 
Table B2: Non-parametric test of the difference in distributions in the image lottery

\begin{tabular}{lccc}
\hline & All & $\begin{array}{c}\text { price }=2 \\
\text { P-values }\end{array}$ & price $=3$ \\
\hline Catholic = Protestant & 0.71 & 0.5160 & 0.341 \\
Catholic = Voodoo & 0.143 & 0.1047 & 0.697 \\
Voodoo = Protestant & 0.018 & 0.0918 & 0.109 \\
\hline N. & 774 & 490 & 284 \\
\hline
\end{tabular}

Table B3: Non-parametric test of the difference in distributions in the neutral and image lottery

\begin{tabular}{lccc}
\hline & All & $\begin{array}{c}\text { Image Buyers } \\
\text { P-values }\end{array}$ & Non-buyers \\
\hline Neutral = Image (mean) & 0.0000 & 0.0000 & 0.0093 \\
Neutral = Voodoo Image & 0.0022 & 0.0303 & 0.0357 \\
Neutral = Protestant Image & 0.0000 & 0.0000 & 0.0626 \\
Neutral = Catholic Image & 0.0000 & 0.0000 & 0.0301 \\
\hline N. & 774 & 461 & 313 \\
\hline Notes: The table reports significance tests of the difference of the distribution of \\
the bets, expressed as share of the endowment, for neutral and image lottery for \\
all and by type of players (buyers and non-buyers).
\end{tabular}

Table B4: Mean and Wilcoxon distribution test for the share bet with different price treatments

\begin{tabular}{lcccc}
\hline & price $=2$ & price $=3$ & \multicolumn{2}{c}{ P-values } \\
& & & Distribution & Mean \\
\hline Neutral & 0.53 & 0.52 & 0.6536 & 0.6169 \\
\hline $\mathrm{N}$. & 490 & 284 & & \\
\hline $\begin{array}{l}\text { Notes: The Table presents for each of the price treatments the } \\
\text { mean of the share bet in neutral and images lotteries. The Dis- } \\
\text { tribution test is a Wilcoxon distribution test and the Mean test is } \\
\text { the t-test. }\end{array}$
\end{tabular}




\section{Theory}

\section{C.1 General}

Consider a lottery in which the subject has an endowment $e$, and can choose to keep some of this or allocate a stake $b$ to a lottery that pays a multiple of the stake $m b$ with a probability that the individual believes to be $p$.

The lottery pays zero otherwise. Let us first consider the case where purchasing a religious image is not an option. We refer to this setting as "neutral". Assuming the players are expected utility maximizers, the maximization problem of any of them in the neutral lottery is:

$$
\operatorname{Max}_{b} E U(b)=(1-p) u(e-b)+p u(e+(m-1) b)
$$

where $u(x)$ is the Von Neumann-Morgenstern (VNM) utility function characterizing the individual attitude towards risk and $p$ his/her probability of winning the lottery. If there is an interior solution, the first order condition of this problem is

$$
\frac{d E U(b)}{d b}=-(1-p) u^{\prime}(e-b)+(m-1) p u^{\prime}(e+(m-1) b)=0 .
$$

There might also be corner solutions where the individual bets everything if $\frac{d E U(b)}{d b}>0$ $\forall b \in[0, e]$, or nothing if $\frac{d E U(b)}{d b}<0 \forall b \in[0, e]$. From this we can show the following result.

Lemma 1 For continuous betting strategies, any individuals who bets zero in the lottery must believe the lottery is weakly actuarially unfair, i.e. must believe that $p \leq \frac{1}{m}$

Proof of Lemma 1: First, weakly risk-loving individuals bet everything $b=e$ if $E b=p m b>b$. Secondly, for risk-averse individuals to bet zero it must be the case that $\frac{d E U(b)}{d b} \leq 0$ for all $b \in[0, e]$. If $u(b)$ is weakly concave then $\frac{d E U(b)}{d b}$ is weakly decreasing in $b$. It is nonpositive everywhere if and only if it is nonpositive at $b=0$, so that $\frac{d E U(b)}{d b}_{b=0}=-(1-p) u^{\prime}(e)+(m-1) p u^{\prime}(e)=-(1-p m) u^{\prime}(e) \leq 0$.

This implies that $\frac{d E U(b)}{d b}_{b=0} \leq 0$ if and only if $m p \leq 1$. QED. 


\section{C.2 Exploiting the neutral lottery game}

The subjects have an endowment of $e=10$ coins that they can share as they wish between keeping it (no risk but low return) and the risky lottery, which has a high return (i.e. a return of 2 for an investment of 1 with a probability of success of 0.6). In other words, our lottery is actuarially more than fair (i.e., $0.6>\frac{1}{2}$ ) so that, by virtue of Lemma 1 each player would like to bet something positive if continuous bets are allowed. ${ }^{23}$

One concern with this result is that, because the lemma holds for continuous betting strategies, it does not necessarily apply to experimental settings where subjects bet in discontinuous units of $0,1,2,3 \ldots$. Our subjects have to solve (7) for $b \in\{0,1, \ldots, 10\}$. Even if some strictly positive bet greater than zero but less than one would be preferable, a subject may bet zero because it is preferable to betting the smallest discrete positive bet available.

The first point revealed by our experiment is that close to 6 percent of the players do not bet anything in the neutral lottery game. Betting 0 might reflect the fact that our subjects being forced to bet either 0 or 1 they prefer betting 0 than 1 . For this to be true it must be the case that $u(10)>0.4 u(9)+0.6 u(11)$, which is equivalent to $\frac{u(10)-u(9)}{u(11)-u(10)}>1.5$.

To exploit our empirical observations we assume, as it is standard in the literature, that the preferences of our subjects are represented by a CRRA utility function: $u(x)=$ $\frac{x^{1-\rho}}{1-\rho}$ with $\rho>0$ and $\rho \neq 1$. Substituting the CRRA utility function in (7) and $e=10$ optimization with respect to $b$ yields as FOC:

$$
E U^{\prime}(b)=-(1-p)(10-b)^{-\rho}+p(10+b)^{-\rho}
$$

where $p$ denotes the individual's probability of winning the lottery.

\footnotetext{
${ }^{23}$ Whatever the Von Neumann-Morgenstern (VNM) utility function characterizing the individual attitude towards risk it cannot lead to a continuous bet of 0 if the individual believes that $\hat{p}=p=0.6$. FOC yields $\frac{d E U(b)}{d b}=-0.4 u^{\prime}(10-b)+0.6 u^{\prime}(10+b)=0$, which is sufficient as $u(x)$ is strictly concave. With our specification of the lottery there is always a value of $b>0$ such that the FOC holds.
} 
When $\rho>0$ we obtain an interior solution for $b$ such that $E U^{\prime}(b)=0$. Let

$$
q=\min \left\{1,\left(\frac{1-p}{p}\right)^{\frac{1}{\rho}}\right\}
$$

We deduce that the optimal betting strategy $b_{0}$ for an individual characterized by a CRRA utility function with parameter $\rho \in(0,+\infty)$ and probability of winning $p$ is:

$$
b_{0}=\frac{10(1-q)}{1+q}
$$

It is easy to check that if $p=0.6$ then $\lim _{\rho \rightarrow 0} b_{0}=10$ and $\lim _{\rho \rightarrow+\infty} b_{0}=0$.

The FOC in (2) is equivalent to:

$$
q\left(b_{0}\right)=\frac{10-b_{0}}{10+b_{0}}
$$

From an empirical point of view the observation of the betting strategy of the players, $b_{0}$, in the neutral lottery game, allows us to deduce the value of $q_{0}=q\left(b_{0}\right)$, which is a combination of the individual's perceived probability of winning the lottery and their risk aversion. In particular if they bet 0 it implies that $q_{0}=1$. We exploit the betting behavior of the subjects in the neutral lottery game to compute $q_{0}=q\left(b_{0}\right)$ according to (4) for each subject.

\section{C.3 Exploiting the lotteries with images}

We exploit next the games where the players are obliged to buy an image. Let $t \in\{2,3\}$ denote the price of the religious image. The FOC for the betting behavior of players who do not update their probability of winning the lottery, nor their risk aversion, in the presence of religious image which cost $t \in\{2,3\}$ is:

$$
E U^{\prime}(b)=-(1-p)(10-t-b)^{-\rho}+p(10-t+b)^{-\rho}
$$

Let $q$ be the solution to equation (3). We deduce that the optimal betting strategy for an individual characterized by a CRRA utility function with parameter $\rho \in(0,+\infty)$ and probability of winning $p$ and income $10-t$ is: $b(t)=\frac{(10-t)(1-q)}{1+q}$. 
Substituting $q_{0}$ from (4) computed with $b_{0}$, the betting behavior of our subjects in the neutral case, we compute for each player:

$$
b(t)=\frac{(10-t)\left(1-q_{0}\right)}{1+q_{0}} .
$$

To make comparisons of betting behavior meaningful we compute the percentage of the net endowment that each player gambles in each game. In the neutral game this percentage is simply obtained by multiplying $b_{0}$, the amount gambled in the neutral game by 10: $x_{0}=10 b_{0}$. In the games with the images, the endowment is lower by either $20 \%$ or $30 \%$ (we can call this a revenue effect). Let $t=2$ or $t=3$ be the randomized cost of playing with a religious image, and let $b_{t}$ be the actual bet chosen by the player when $t \in\{2,3\}$. The percentage of the net endowment gambled by the player is $x_{t}=\frac{100 b_{t}}{10-t}$.

It is straightforward to check that if $b_{t}=b(t)$ (i.e., if the player does not update his/her subjective probability of winning the lottery, nor his/her risk aversion, in presence of religious image) then $x_{t}=x_{o}$. In other words if only a revenue effect is in play then the individuals should not change the percentage of their endowment they allocate to the gamble. We know from section 4 that our individuals bet a larger share of their endowment in presence of religious images so that on average $b_{t}>b(t)$.

\section{Questionnaire on religious practices}

Note that the number in parenthesis refers to the number of the given question in the original questionnaire. The questions were interspersed so as not to give undue prominence to any one theme.

\section{Bloc 1: Voodoo religious practice}

1. (Q15) At the last birth of a child in your family, what medical care did you have?

- Hospital or clinic

- Doctor or nurse

- Midwife 
- Traditional doctor ("levepye") $\Longrightarrow$ A dummy variable takes the value 1 for those who give this reply.

2. (Q17) What did you do to protect the child against jalousie, Djok, Lougawou?

- Prayer

- Bath $\Longrightarrow$ A dummy variable takes the value 1 for those who give this reply.

- Mystical object (collier, centure de Djok, ...)

3. (Q17) What did you do to protect the child against jalousie, Djok, Lougawou?

- Prayer

- Bath

- Mystical object (collier, centure de Djok, ...) $\Longrightarrow$ A dummy variable takes the value 1 for those who give this reply.

4. (Q18) In your opinion, what was the cause of the death of the last close person you lost?

- Natural

- Supernatural $\Longrightarrow$ A dummy variable takes the value 1 for those who give this reply.

5. (Q19) Which ceremonies did you perform for that person?

- Measuring the body ("retemo") $\Longrightarrow$ A dummy variable takes the value 1 for those who give this reply.

- Vigil ("veillée")

- Funeral

- Last prayers

6. (Q31) Concerning the last case of serious illness in your family, what was the cause of that sickness? 
- Natural

- Supernatural $\Longrightarrow$ A dummy variable takes the value 1 for those who give this reply.

7. (Q33) Where did you go with this person for medical care?

- Hospital or clinic

- Church

- Doctor or nurse

- Traditional doctor ("levepye") $\Longrightarrow$ A dummy variable takes the value 1 for those who give this reply.

8. (Q34) What measures did you take to protect this person against future sickness?

- None

- Modern medicine

- Traditional medicine

- Both $\Longrightarrow \mathrm{A}$ dummy variable takes the value 1 for those who give this reply or "Traditional Medicine"

9. (Q37) If you or a member of your family has been the victim of physical violence, to whom did you go for help?

- Nobody

- Police, lawyer, state authority

- Family, friends

- Priest or Pastor

- Traditional Practitioner $\Longrightarrow$ A dummy variable takes the value 1 for those who give this reply.

10. (Q45) In which type of ceremonies do you participate in your village? 
- Protestant church

- Catholic church

- Fête patronale

- Guede (voodoo dance and ceremonies) $\Longrightarrow$ A dummy variable takes the value 1 for those who give this reply.

11. (Q40) If you or a member of your family has been the victim of theft, to whom did you go for help?

- Nobody

- Police, lawyer, state authority

- Family, friends

- Priest or Pastor

- Traditional Practitioner $\Longrightarrow$ A dummy variable takes the value 1 for those who give this reply.

\section{Bloc 2: General religiosity}

1. (Q17) What did you do to protect the last child born in your family child against jalousie, Djok, Lougawou?

- Prayer $\Longrightarrow$ A dummy variable takes the value 1 for those who give this reply.

- Bath

- Mystical object (collier, centure de Djok, ...)

2. (Q19) Which ceremonies did you perform for the last close person you lost?

- Measuring the body ("retemo")

- Vigil ("veillée") $\Longrightarrow$ A dummy variable takes the value 1 for those who give this reply.

- Funeral 
- Last prayers

3. (Q19) Which ceremonies did you perform for the last close person you lost?

- Measuring the body ("retemo")

- Vigil ("veillée")

- Funeral $\Longrightarrow$ A dummy variable takes the value 1 for those who give this reply.

- Last prayers

4. (Q19) Which ceremonies did you perform for the last close person you lost?

- Measuring the body ("retemo")

- Vigil ("veillée")

- Funeral

- Last prayers $\Longrightarrow$ A dummy variable takes the value 1 for those who give this reply.

5. (Q20) Do you clean the tomb of the deceased person every year?

- Yes $\Longrightarrow$ A dummy variable takes the value 1 for those who give this reply.

- No

6. (Q33) Where did you take the last person with a serious illness for medical care?

- Hospital or clinic

- Church $\Longrightarrow$ A dummy variable takes the value 1 for those who give this reply.

- Doctor or nurse

- Traditional doctor ("levepye")

7. (Q37) If you or a member of your family has been the victim of physical violence, to whom did you go for help?

- Nobody 
- Police, lawyer, state authority

- Family, friends

- Priest or Pastor $\Longrightarrow$ A dummy variable takes the value 1 for those who give this reply.

- Traditional Practitioner

8. (Q23) Do you take into account the moon when you plant crops?

- Yes $\Longrightarrow$ A dummy variable takes the value 1 for those who give this reply.

- No

9. (Q45) In which type of ceremonies do you participate in your village?

- Protestant church $\Longrightarrow$ A dummy variable takes the value 1 for those who give this reply.

- Catholic church

- Fête patronale

- Guede (voodoo dance and ceremonies)

10. (Q45) In which type of ceremonies do you participate in your village?

- Protestant church

- Catholic church $\Longrightarrow$ A dummy variable takes the value 1 for those who give this reply.

- Fête patronale

- Guede (voodoo dance and ceremonies)

11. (Q44) In which type of social organization do you participate in your village?

- Religious organization $\Longrightarrow$ A dummy variable takes the value 1 for those who give this reply.

- Political organization 
- Cooperative

- Rotating savings and credit association

12. (Q30) What measures do you take to protect your business activities from theft?

- None

- Lucky objects

- Prayer $\Longrightarrow$ A dummy variable takes the value 1 for those who give this reply.

13. (Q40) If you or a member of your family has been the victim of theft, to whom did you go for help?

- Nobody

- Police, lawyer, state authority

- Family, friends

- Priest or Pastor $\Longrightarrow \mathrm{A}$ dummy variable takes the value 1 for those who give this reply.

- Traditional Practitioner 